\title{
CHRONIC EFFECTS OF INDIRECT AND DIRECT CANNABINOID RECEPTOR AGONISTS ON ADDICTION-RELATED BEHAVIORS AND DOPAMINE RELEASE
}

Kevin M. Honeywell, Timothy G. Freels, Megan A. McWain, Abigail S. Chaffin, Hunter G.

Nolen, Helen J. Sable, \& Deranda B. Lester*

Department of Psychology, the University of Memphis, Memphis, TN, USA

*Corresponding author:

Dr. Deranda Lester

Department of Psychology

The University of Memphis

Memphis, Tennessee

USA 38152-6400

tel: (901) 678-4213

fax: (901) 678-2579

email: dbrewer@memphis.edu

Abbreviations: 2-AG, 2-arachidonoylglycerol; AA-5-HT, $N$-arachidonoyl serotonin; ACEA, arachidinoyl-2'chloroethylamide; AEA, arachidonoylethanolamide; $\mathrm{B} 6, \mathrm{C} 57 \mathrm{BL} / 6 \mathrm{~J}$ mice; $\mathrm{CB}_{1} \mathrm{R}$, cannabinoid type 1 receptor; $\mathrm{CB}_{2} \mathrm{R}$, cannabinoid type 2 receptor; CPA, conditioned place aversion; CPP, conditioned place preference; DAR, dopamine autoreceptor; DAT, dopamine transporter; $\mathrm{D}_{2} \mathrm{R}$, dopamine receptor $\mathrm{D}_{2} ; \mathrm{D}_{3} \mathrm{R}$, dopamine receptor $\mathrm{D}_{3} ; \mathrm{eCB}$, endocannabinoid; EPM, elevated plus maze; FAB5, fatty acid binding protein-5; FAB7, fatty acid binding protein 7; FAAH, fatty acid amide hydrolase; LDB, light/dark box; MAGL, monoacylglycerol lipase; NAc, Nucleus accumbens; OF, open field, THC, $\Delta^{9}$-tetrahydracannabinol; TRPV ${ }_{1}$, transient receptor potential vanilloid type 1 channel; VTA, ventral tegmental area anad 


\section{Highlights}

- The indirect cannabinoid agonist AA-5-HT did not alter dopamine release or measured behaviors.

- The direct cannabinoid receptor agonist ACEA did not alter measured behaviors.

- ACEA decreased dopamine release and the dopaminergic response to cocaine.

- Neither drug indicated abuse liability, although ACEA did alter dopamine functioning. 


\begin{abstract}
A major problem with current anxiolytic medications is abuse liability; thus, new pharmaceutical targets are being explored. The cannabinoid system is one potential target. The current paper examined behavioral and neurochemical changes related to abuse liability following chronic administration of the indirect cannabinoid agonist arachidonoyl serotonin (AA-5-HT) and the direct cannabinoid type 1 receptor $\left(\mathrm{CB}_{1} \mathrm{R}\right)$ agonist arachidonyl-2-chloro-ethylamide (ACEA). AA-5-HT indirectly agonizes the cannabinoid system via inhibition of the dual fatty acid amide hydrolase (FAAH) while also inhibiting transient vanilloid type $1\left(\mathrm{TRPV}_{1}\right)$ channels. Neither AA-5-HT nor ACEA induced conditioned place preference (CPP) or altered behaviors during open field (OF) or saccharin preference testing. AA-5-HT did not alter phasic dopamine release in the nucleus accumbens, as measured with in vivo fixed potential amperometry; however, ACEA decreased dopamine release and enhanced the dopaminergic effect of cocaine. Overall, neither AA-5-HT nor ACEA induced behavioral or neurochemical changes associated with abuse liability; however, indirect mechanisms of agonizing the cannabinoid system may be a better alternative than direct mechanisms if concerned with disrupting dopamine function.
\end{abstract}

Keywords: Cannabinoid, Dopamine, Electrophysiology, Anxiety, Addiction, Nucleus accumbens 
Chronic Effects of Indirect and Direct Cannabinoid Receptor Agonists on Addiction-Related Behaviors and Dopamine Release

\section{Introduction}

The treatment of anxiety requires novel therapeutics. Anxiety is an anticipatory process typically associated with an overestimation of the danger of possible, future threats in which individuals predict aversive events or fail to recognize safety signals, causing disinhibition of the default neurobiological stress response and leading to muscle tension and vigilance $[1,2]$. The treatment of anxiety is an expensive, costing an estimated $\$ 33$ billion annually, and prevalent, directly effecting $18.1 \%$ of the United States of America's adult population, health issue $[3,4]$. The current therapeutics for the treatment of anxiety are addictive and deadly (benzodiazepines) or ineffective (selective serotonin reuptake inhibitors) [5-11]. Therefore, novel therapeutics are being explored for the treatment of anxiety, and the cannabinergic system is a promising target, which could provide anxiolytic effects without the drawbacks of benzodiazepines and antidepressants.

The cannabinergic system consists of two primary types of cannabinoid receptors type 1 $\left(\mathrm{CB}_{1} \mathrm{Rs}\right)$ and type $2\left(\mathrm{CB}_{2} \mathrm{Rs}\right)$, with $\mathrm{CB}_{1} \mathrm{Rs}$ being the main target for anxiolytic effects. $\mathrm{CB}_{1} \mathrm{Rs}$ are predominately expressed in the central nervous system where they are found in high densities in brain regions associated with the regulation of emotional process including anxiety such as the prefrontal cortex, basolateral amygdala, and ventral hippocampus and at significantly higher levels on GABAergic than glutamatergic neurons [12-15]. Postsynaptic neuron depolarization triggers the release of endocannabinoids (eCBs) including $\mathrm{N}$-arachidonoylethanolamide (AEA) that binds to $\mathrm{CB}_{1} \mathrm{Rs}$ and 2-arachidonoylglycerol (2-AG) that binds to $\mathrm{CB}_{1 / 2} \mathrm{Rs}$, which both inhibit presynaptic neurotransmission before being trafficked by fatty acid binding protein-5 
(FAB5) and fatty acid binding protein-7 (FAB7) and metabolized by fatty acid amide hydrolase (FAAH) in presynaptic terminals and monoacylglycerol lipase (MAGL) in postsynaptic terminals respectively $[12,13,16-25]$. The pharmacological manipulation of the cannabinoid system can be used as a target for anxiolytic treatment. Rodent studies indicate that pharmaceutically stimulating $\mathrm{CB}_{1}$ Rs or increasing eCB levels (via inhibition of FAAH or eCB transporters) promote anxiolytic-like behaviors in the elevated plus maze (EPM), open field (OF), and light/dark box (LDB) [26-29]. Though, it is important to note that $\mathrm{CB}_{1} \mathrm{R}$ agonists act in a dose-dependent manner where lower doses are anxiolytic and higher doses can be anxiogenic [30,31]. Therefore, in finding potential pharmacological treatments for anxiety, it is paramount to ascertain the correct dosage in order to prevent the inverse of the desired effect. The neuropharmacology of eCBs is further complicated when considering other receptor types activated by eCBs.

The transient receptor potential cation channel subfamily V member $1\left(\mathrm{TRPV}_{1}\right)$ is another target for altering neurotransmission and potentially alleviating anxiety as eCB activation of these receptors is anxiogenic. Antagonists of TRPV 1 s are potentially anxiolytic. For example, capsazepine, a TRPV 1 antagonist, induced anxiolytic-like behaviors in the EPM [28,32,33]. Additionally, $\mathrm{TRPV}_{1}$ knockout mice expressed more anxiolytic-related behaviors in LDB and EPM [34]. Therefore, the TRPV 1 may be a target for antagonism in the treatment of anxiety. Though, the modulation of $\mathrm{TRPV}_{1}$ is complicated due to some agonists at this receptor also agonizing $\mathrm{CB}_{1} \mathrm{R}$. Importantly, the eCB AEA is an agonist for both $\mathrm{CB}_{1} \mathrm{Rs}$ and $\mathrm{TRPV} \mathrm{V}_{1} \mathrm{~S}$ [3539]. Additionally, $\mathrm{CB}_{1}$ Rs and $\mathrm{TRPV}_{1} \mathrm{~s}$ are co-localized in the nucleus accumbens (NAc) shell (predominately) and core of mice [40]. Therefore, eCBs can modulate activity at these receptors in areas implicated in reward. 
Indirect (via the administration of FAAH inhibitors or $\mathrm{TPRV}_{1}$ antagonists) and direct (via the administration of $\mathrm{CB}_{1} \mathrm{R}$ agonists) agonism of the cannabinoid system can be potentially utilized in the treatment of anxiety. The dual FAAH/TRPV 1 inhibitor $\mathrm{N}$-arachidonoyl serotonin (AA-5-HT) and the $\mathrm{CB}_{1} \mathrm{R}$ direct agonist with some affinity to TRPV 1 arachidonoyl-2'chloroethylamide (ACEA) have been shown to elicit modest anxiolytic effects in rodent models [25-27,40-45]. However, the abuse potential of drugs that indirectly and directly agonize the cannabinoid system is still under investigation.

The mesolimbic dopamine pathway is utilized to explore the addictive potential of posited pharmaceuticals and drugs of abuse. The dopamine system is comprised of dopamine transporters (DATs), D1-like receptors (D1 and D5), D2-like receptors (D2, D3, and D4), the latter of which includes dopamine autoreceptors (DARs) [46-49]. Acute drug administration including cocaine and amphetamine enhance the strength of excitatory synapses on midbrain dopamine neurons, which are associated with the salience of predicted cues for reward including drugs of abuse [50-52]. The modulation of this pathway has been implicated in the rewarding nature of cannabinoids $[54,55]$. Therefore, discerning the utility of indirectly and directly agonizing the cannabinoid system for anxiety requires delineating the alterations in dopamine signaling as a sign of abuse potential.

The cannabinergic system and dopaminergic system are intertwined. Indirect cannabinoid agonism alters dopaminergic signaling. URB597 (FAAH inhibitor) pretreatment before AEA administration but not URB597 treatment alone potentiated AEA-induced extracellular dopamine in the NAc shell [56]. AM-404 (AEA transporter inhibitor) pretreatment dose-dependently blocked cocaine (DAT blocker)-induced hyperlocomotion [57]. On the fifth through eighth day, chronic URB597 pretreatment blocked d-amphetamine-induced 
hyperlocomotion [58]. URB597 administration with quinpirole (D2/3R agonist) also blocked quinpirole-induced hyperlocomotion and dose-dependently attenuated quinpirole-induced decreases in extracellular dopamine in the NAc $[59,60]$. However, these effects may be timeand dose-dependent as URB597 before a non-sensitizing dose of cocaine followed $24 \mathrm{~h}$ later by a sensitizing dose of cocaine increased cocaine-induced hyperlocomotion and dopamine release in the NAc core [61].

Furthermore, direct cannabinoid agonism alters dopaminergic signaling. AEA administration increased NAc shell extracellular dopamine [56]. Chronic $\Delta 9$ tetrahydracannabinol (THC) (direct CB1R agonist) administration upregulated $\mathrm{D}_{3} \mathrm{R}$ messenger ribonucleic acid and postsynaptic $\mathrm{D}_{3} \mathrm{R}$ agonist binding in the NAc and increased postsynaptic and presynaptic $\mathrm{D}_{2 / 3} \mathrm{R}$ antagonist and $\mathrm{D}_{3} \mathrm{R}$ agonist binding in the ventral tegmental area (VTA), leading to super-sensitization [62]. Chronic THC pretreatment did not affect basal dopamine levels in the NAc core [63]. WIN55,212-2 dose-dependently decreased locomotion and decreased medial forebrain bundle (MFB) stimulated NAc core dopamine release [64]. ACEA (direct CB1R agonist) did not alter locomotion but did decrease VTA stimulated NAc core dopamine release [27]. Additionally, WIN55,212-2 (CB1R agonist) blocked cocaine-induced hyperlocomotion [57]. However, these effects may also be time- and dose-dependent as chronic THC pretreatment followed by a THC drug challenge during microdialysis increased extracellular dopamine in the NAc core and chronic THC followed two days later with a damphetamine drug challenge during microdialysis increased d-amphetamine-induced hyperlocomotion but did not alter dopamine in the NAc $[63,65]$. Therefore, there is a crossmodulation between the cannabinergic and dopaminergic systems that requires assessment for 
the abuse potential of posited anxiolytic drugs that indirectly and directly agonize the cannabinergic system.

Additionally, the reduction in dopamine following cannabinoid administration may be indicative of anhedonia. Anhedonia is a reduction in the ability to experience pleasure or a diminished interest in pleasurable activities [66]. A two-bottle choice test for a sweet liquid can be utilized to explore the role of drug administration on anhedonia, and saccharin a non-nutritive sweet liquid can be rewarding $[67,68] \mathrm{CB}_{1} \mathrm{R}$-knockout on $\mathrm{D}_{1} \mathrm{R}$ expressing neurons mildly reduced sucrose preference [69]. THC administration induced a conditioned taste aversion to sucrose and saccharin [70-72]. However, the aversive nature of cannabinoids with regards to taste preference may be time dependent as pretreatment every other day for 12 days with THC attenuated the THC conditioned taste aversion to saccharin [71]. Anhedonia-related behaviors may be associated with reductions in dopaminergic signaling as research using optogenetics has shown that antagonism of $\mathrm{D}_{1} \mathrm{Rs}$ in the NAc ablated basolateral amygdala to NAc excitation and inhibition of the basolateral amygdala to NAc pathway attenuated licking for a sucrose reward [73]. $\mathrm{CB}_{1} \mathrm{R}$ agonist administration attenuated dopamine release in the NAc of mice and rats $[27,64]$. Therefore, reducing the activation of $\mathrm{D}_{1} \mathrm{Rs}$ through antagonism or through synaptic dopamine reductions by $\mathrm{CB}_{1} \mathrm{R}$ indirect or direct agonism may lead to anhedonia.

\subsection{Current study}

The current study explored the addictive potential of the indirect cannabinoid agonist AA-5-HT and the direct cannabinoid agonist ACEA. Specifically, the project determined the effect of repeated AA-5-HT or ACEA administration on NAc dopamine transmission, using in vivo fixed amperometry, and related behaviors (locomotor activity, conditioned place preference (CPP), and saccharin preference). Mice were pretreated with a chronic, seven-day dose of either 
AA-5-HT, ACEA, or vehicle (negative control). As mentioned above, Freels and colleagues from our lab [27] have done similar experiments with AA-5-HT and ACEA, using only acute injections, finding both drugs decrease NAc dopamine release. The current study is more generalizable compared to our previous study by using dosing more applicable to the human population (chronic use). Chronic administration of these drugs also allows us to address the aforementioned issues of sensitization. To determine cross-sensitization effects between the cannabinoid and dopamine systems, a subset of mice was administered the dopamine reuptake blocker cocaine during amperometric recordings. Overall, this study examines the effects of chronic cannabinoid activation (by both indirect and direct agonists) on the mesolimbic dopamine system and the way this pathway responds to a dopamine agonist.

\section{Method}

All procedures have been approved by the Institutional Animal Care and Use Committee (IACUC) at the University of Memphis and were also aligned with those outlined in The Public Health Service Policy on Humane Care and Use of Laboratory Animals (National Institutes of Health, 2012) and the Guidelines for the Care and Use of Mammals in Neuroscience and Behavioral Research (National Research Council, 2003). The current study was split into two major experiments. In the first, mice underwent chronic, seven-day drug treatment, OF testing on day one and day seven, and then in vivo fixed potential amperometry for dopamine recordings on day eight. In the second, mice underwent CPP for eight days followed by two-bottle choice test between saccharin and water for five days. 


\subsection{Animals}

Fifty-four, male C57BL/6J mice $(n=54)$ for the first experiment and 27, male C57BL/6J mice $(n=27)$ for the second experiment were obtained from Jackson Laboratory (Bar Harbor, $\mathrm{ME}$ ) and were housed 2-5 per cage in $18.5 \times 29.5 \mathrm{~cm}$ polycarbonate Generic State Microisolators with Sani-Chips bedding (P.J. Murphy Forest Products, Montville, New Jersey). Food and water were available ad libitum. Mice were housed in a temperature-controlled room $\left(21 \pm 1^{\circ} \mathrm{C}\right)$ with a $12 \mathrm{~h}$ light: $12 \mathrm{~h}$ dark cycle. At the time of drug treatments and experiments, mice were 3 to 5 months old (adults).

\subsection{Experiment 1 (Locomotor Activity and Dopamine Release)}

\subsubsection{Chronic Drug Treatments}

For the first experiment, mice were randomly selected to receive one of three chronic treatments. Chronic drug treatments consisted of one i.p. injection per day for seven days of either AA-5-HT (2.5 mg/kg, $n=19)$, ACEA (1.0 mg/kg, $n=15)$, or vehicle comprised of 10\% dimethyl sulfoxide (DMSO) in saline $(n=20)$ all acquired from Sigma Aldrich (St. Louis, MO). This amount of AA-5-HT reflects the dose that was utilized by Micale et al. [40] and caused behavioral changes related to anxiety in both B6 and Swiss mice. This amount of ACEA reflects the dose that was utilized by Rutkowska and Jachimczuk [44] and Freels, Lester, and Cook [27], which trended to or moderately caused behavioral changes related to stress. On the eighth day, during dopamine recordings, mice received an i.p. injection of either AA-5-HT $(2.5 \mathrm{mg} / \mathrm{kg}, n=$ 13), $\operatorname{ACEA}(1.0 \mathrm{~m} / \mathrm{kg}, n=9)$, cocaine $(10.0 \mathrm{mg} / \mathrm{kg}, n=17)$ or vehicle $(n=15)$. As can be seen in Table 1, the ten total groups encompassed AA-5-HT-AA-5-HT $(n=7)$, AA-5-HT-vehicle $(n=$ 6), AA-5-HT-cocaine $(n=6)$, ACEA-ACEA $(n=5)$, ACEA-vehicle $(n=5)$, ACEA-cocaine $(n=$ 5), vehicle-AA-5-HT $(n=6)$, vehicle-ACEA $(n=4)$, vehicle-vehicle $(n=4)$, and vehicle-cocaine 
$(n=6)$ where the first drug represents that given during behavioral testing and the second drug represents that given during in vivo fixed potential amperometry. For, the second experiment, mice were also randomly selected to receive one of three chronic treatments. Chronic drug treatments consisted of one i.p. injection every other day for six days, two days off, then five days of either AA-5-HT (2.5 mg/kg, $n=9)$, ACEA (1.0 mg/kg, $n=9)$, or vehicle $(n=9)$ all acquired from Sigma Aldrich (St. Louis, MO). To minimize outside anxiogenic variables, drug treatments were administered by the same person, at the same time each day.

\subsubsection{OF Testing}

For the first experiment, mice were tested in the OF chamber twice, once on the first day of the chronic drug treatment and again on the seventh day of treatment. On test day, each mouse was placed in a single holding cage inside a sound attenuated cabinet in the testing room for $45 \mathrm{~min}$ in order to habituate the mouse. At the beginning of each OF test, the mouse was placed in the center of the OF chamber. The OF apparatus was a HamiltonKinder SmartFrame ${ }^{\mathrm{TM}}$ (HamiltonKinder, Poway, CA) with a clear Plexiglass insert with dimensions of $24.13 \mathrm{~cm} \mathrm{x}$ $45.72 \mathrm{~cm}$, a $4 \times 8$ photo beam strip, and a $4 \times 8$ photo beam rearing attachment. During the session, software (MotorMonitor verison 4.14, HamiltonKinder, Poway, CA) tracked the time spent in the central area, time spent outside of the central area, rearing, and total distance travelled. The central area specified in the software's zone map function was a of $9 \mathrm{~cm} \mathrm{x} 10 \mathrm{~cm}$ space positioned $4.5 \mathrm{~cm}$ from the left and right walls and $15 \mathrm{~cm}$ from the front and back walls of the chamber. After a 20 min baseline movement assessment, the mouse received an i.p. injection of the assigned chronic treatment (AA-5-HT, ACEA, or vehicle) and testing continued for 90 min post-injection. At the end of the test, each mouse was returned to its home cage in the 
mouse colony. The OF chamber was then cleaned with $10 \%$ isopropyl alcohol and allowed to dry after each trial.

\subsubsection{Dopamine Recordings}

For the first experiment, on the eighth day of the chronic drug treatments, all mice underwent stereotaxic surgery for the measurement of dopamine transmission using in vivo fixed potential amperometry. Mice were permanently anaesthetized with urethane (1.5 g/kg, i.p.). The dose of which was split into two i.p. injections separated by $10 \mathrm{~min}$. Fifteen min following the second injection, mouse anesthesia was assessed through eye blink, mild tail pinch, and mild foot pinch reflexes. Mice were mounted into a stereotaxic frame (David Kopf Instruments, Tujunga, CA), and their body temperature was kept at approximately $37^{\circ} \mathrm{C}$. A stimulating electrode (SNE-100; Rhodes Medical Co., Summerland, CA) was placed into the left VTA (coordinates in mm from bregma: $\mathrm{AP}-3.3, \mathrm{ML}+0.3$, and $\mathrm{DV}-4.0$ from dura) [74]. $\mathrm{A} \mathrm{Ag} / \mathrm{AgCl}$ reference and stainless-steel auxiliary electrode combination was placed on contralateral cortical tissue -2.0 $\mathrm{mm}$ to bregma, and a carbon fiber recording electrode (500 um length $\mathrm{x} 7$ um o.d.; Union Carbide, North Seadrift, TX) was positioned in the left NAc (coordinates in mm from bregma: $\mathrm{AP}+1.5, \mathrm{ML}+1.0$, and $\mathrm{DV}-4.0$ from dura) [69]. A series of cathodal current pulses was delivered to the stimulating electrode via an optical stimulus isolator and programable pulse generator (Iso-Flex/Master 8; AMPI, Jerusalem Israel), which stimulated dopamine release. A fixed $+0.8 \mathrm{~V}$ current was continuously applied to the recording electrode, which oxidized the dopamine. The change in current due to the oxidation of dopamine was monitored by the electrometer (ED401 e-corder and EA162 Picostat, eDAQ Inc., Colorado Springs, CO) filtered at $50 \mathrm{~Hz} \mathrm{10,000} \mathrm{times} \mathrm{per} \mathrm{second.}$ 
Stimulation parameters varied depending on the aspect of dopamine transmission being measured. Initially, while establishing a baseline response, the stimulation protocol consisted of 20 monophasic $0.5 \mathrm{~ms}$ duration pulses $(800 \mu \mathrm{Amps})$ at $50 \mathrm{~Hz}$. DAR sensitivity was assessed by applying a pair of test stimuli (T1 and T2, each 10 pulses at $50 \mathrm{~Hz}$ with $10 \mathrm{sec}$ between $\mathrm{T} 1$ and T2) to the VTA every $30 \mathrm{sec}$ [65-67]. Six sets of conditioning pulses (1, 5, 10, 20, 40, and 80; $0.5 \mathrm{~ms}$ pulse duration at $15 \mathrm{~Hz}$ ) were delivered prior to $\mathrm{T} 2$ such to leave $0.3 \mathrm{~s}$ between the end of the conditioning pulse train and initiation of T2. DAR-mediated inhibition of evoked dopamine efflux was expressed in terms of the change in the amplitude of $\mathrm{T} 2$ with respect to $\mathrm{T} 1$ for each set of conditioning pulses; low-to-high DAR sensitivity was represented as low-to-high percent inhibition of evoked dopamine efflux (i.e. high sensitivity results in lower amplitude of T2 relative to $\mathrm{T} 1)$.

Upon completion of the autoreceptor sensitivity test, stimulation parameters were reset to 20 pulses at $50 \mathrm{~Hz}$ every $30 \mathrm{sec}$. Following $5 \mathrm{~min}$ of baseline dopamine efflux recording, each mouse was given a drug challenge via an i.p. injection of AA-5-HT (2.5 mg/kg), ACEA (1.0 $\mathrm{mg} / \mathrm{kg})$, cocaine $(10 \mathrm{mg} / \mathrm{kg})$ or vehicle. See Table 1 for the experimental groups. Dopamine recordings continued for 90 min post drug challenge for AA-5-HT, ACEA, and vehicle groups and for $60 \mathrm{~min}$ post drug challenge for cocaine groups. After the recordings were complete, direct anodic current of $100 \mu \mathrm{Amps}$ was applied to the stimulating electrode for $10 \mathrm{~s}$ to create an iron deposit, which marked the electrode's position.

Mice were euthanized via an intracardial injection of urethane $(0.345 \mathrm{~g} / \mathrm{mL})$. Brains were removed and stored in 30\% sucrose / $10 \%$ formalin solution with $0.1 \%$ potassium ferricyanide. Coronal sections of each brain were sliced at $-30^{\circ} \mathrm{C}$ using a cryostat, and electrode placements were identified using a light microscope and marked on coronal diagrams [69]. Following the 
experiment, in vitro electrode calibration occurred by recording in solutions of dopamine $(0.2$ $\mu \mathrm{M}-1.2 \mu \mathrm{M})$ via a flow injection system [75-77], which allowed for the conversion of current measurements to dopamine concentrations.

\subsubsection{Data Analyses}

For the first experiment, data was analyzed in two separate sets, one for behavioral data and one for electrochemical data. OF data was analyzed using three-way ANOVAs for day $\mathrm{x}$ block x treatment effects, which includes distance travelled, rears, and percent time in center. Significant treatment differences indicated by $p<.05$ were further explored using Games-Howell post-hoc tests when appropriate. Electrochemical data were broken down into autoreceptor sensitivity, baseline dopamine recordings, and drug challenge recordings. Dopamine oxidation current recordings were used to quantify VTA stimulation-induced dopamine release in the NAc by extracting data points occurring between $0.25 \mathrm{~s}$ pre- and $10 \mathrm{~s}$ post-stimulation at the desired time. DAR sensitivity was assessed by applying a pair of test stimuli (T1 and T2), with a varying number of conditioning pre-pulses prior to T2. Autoreceptor-mediated inhibition of evoked dopamine release was expressed in terms of the percent change between test stimulations (T2/T1x100) for each set of pre-pulses $[76,78,79]$. A two-way mixed ANOVA was used to assess the impact of pretreatment (AA-5-HT, ACEA, or vehicle) and number of pre-pulses on percent inhibition. From baseline (pre drug challenge) recordings, dopamine release was quantified as the magnitude of the response, and dopamine synaptic half-life, an indication of DAT functioning, was quantified as the time for $50 \%$ decrease from the maximum evoked increase to the pre-stimulus level $[66,67]$. One-way ANOVAs, with Tukey's HSD post-hoc tests as needed, were used to determine the effect of drug pretreatment on baseline dopamine release and half-life. During dopamine recordings, mice were administered a drug challenge of either 
AA-5-HT, ACEA, cocaine, or vehicle. Following the drug challenge, data was extracted at 10 min intervals (11 total intervals for AA-5-HT, ACEA, and vehicle and 7 total intervals for cocaine). Change in dopamine release and half-life was expressed as percent change relative to baseline release and half-life (pre-drug $=100 \%$ ). For each drug challenge, a two-way mixed ANOVA was used to assess the impact of drug pretreatment and time post injection on percent change in dopamine release and half-life. A one-way ANOVA was used to test the effects of pretreatment on percent change in dopamine release or half-life at each time point. Significant differences indicated by $p<.05$ were further explored using Tukey's HSD post-hoc or GamesHowell post-hoc tests when appropriate.

\subsection{Experiment 2 (CPP and Saccharin Preference Test)}

\subsection{1. $C P P$}

Experiment 2 aimed to determine whether mice would establish a CPP (or a conditioned place aversion; CPA) for the side paired with either the indirect or direct cannabinoid agonist (AA-5-HT or ACEA, respectively). Prior to each session, each mouse was placed in a single holding cage inside a sound attenuated cabinet in the testing room for $45 \mathrm{~min}$ in order to acclimate the mouse to the new environment. On the first day (habituation), the mouse was placed into the HamiltonKinder SmartFrame ${ }^{\mathrm{TM}}$ (HamiltonKinder, Poway, CA) equipped with an insert to divide the $\mathrm{OF}$ into two halves measuring $21.84 \mathrm{~cm} \times 22.23 \mathrm{~cm}$ each. There was a center

doorway between the two chambers measuring $6.99 \mathrm{~cm}$ (width) x $8.89 \mathrm{~cm}$ (height). The walls of the chamber were covered with either vertical or horizontal black and white bars each measuring $2.54 \mathrm{~cm}$ thick. The vertical bars side was paired with Sani-chips bedding (P.J. Murphy Forest Products, Montville, New Jersey), and the horizontal bars side was paired with So Phresh Natural Softwood bedding (Petco Animals Supplies, San Diego, CA). A black grating covered 
the beddings. Mice were allowed to access both chambers for the $30 \mathrm{~min}$ test period. On conditioning days 2-7, a black, opaque insert was placed over the doorway to restrict movement during the 30 min sessions to only one side. On conditioning days 2, 4, and 6, each mouse was given an i.p. injection of either AA-5-HT (2.5 mg/kg, $n=9)$, ACEA (1.0 mg/kg, $n=9)$, or vehicle $(n=9)$, while on conditioning days 3, 5, and 7 all mice received vehicle. The drug-paired side was counterbalanced for all treatment groups. On the eighth day (test day), the mouse was again placed into the chamber with the door insert removed for $30 \mathrm{~min}$. At the end of each session, each mouse was returned to its home cage in the colony room and the chamber was cleaned with 10\% isopropyl alcohol and allowed to dry.

\subsubsection{Two-Bottle Choice Test}

Additionally, for the second experiment, one day following CPP testing, mice underwent a two-bottle choice test for saccharin or water preference. Saccharin is a non-satiating sweetener for which animals develop a preference [80,81]. A reduction in the preference ratio for saccharin during this test is indicative of anhedonia [67]. At lights on, the mice were weighed, and the water bottles were removed from their home cages. At lights off (12 hours later), the mice were injected with AA-5-HT (2.5 mg/kg, $n=9)$, ACEA (1.0 mg/kg, $n=9)$, or vehicle $(n=9)$ and placed individually into separate cages each containing one bottle of $0.1 \%$ saccharin and one bottle of tap water (both weighed beforehand). After the $2 \mathrm{~h}$ test, mice were returned to their home cage with home cage water bottle replaced. The preference test bottles were then weighed again to determine how much of each had been consumed. To eliminate novelty effects, only the second to sixth day were used to examine group differences. 


\subsubsection{Data Analyses}

For the second experiment, the two sets of behavioral data were analyzed separately. For place preference, potential chamber bias was first examined using a one sample $t$-test comparing the time spent on what was to become the drug-paired side to 900 s (i.e., exactly half of the habituation session time). Next, time spent on the drug-paired side on day one was subtracted from the time spent on the drug-paired side on day eight, and the difference was analyzed by a one-way ANOVA to determine if a CPP or CPA was present. Likewise, the number of entries into the drug-paired side on day one was subtracted from the number of entries into the drug-paired side on day eight, and the difference analyzed by a one-way ANOVA. Locomotor activation was also examined by looking at the total distance travelled $(\mathrm{cm})$ on each of the three drug-paired days and analyzing these data with a two-way ANOVA. For the twobottle choice test, saccharin consumed in $\mathrm{g} / \mathrm{kg}$ body weight and saccharin preference (i.e., percent of total liquid consumed) were analyzed separately by two-way ANOVA.

\section{Results}

\subsection{Experiment 1 (Locomotor Activity and Dopamine Release)}

\subsubsection{OF Testing}

Locomotor activities assessed in the OF included distance travelled $(\mathrm{cm})$, rearing, and percent time spent in center. Baseline locomotor activity was assessed in two 10 min blocks per day. As can be seen in Figure $1 A$, there was not a main effect of pretreatment on distance travelled, $F(2,51)=0.46, p=.67, \eta_{\mathrm{p}}^{2}=.02$. There was not a day x pretreatment $(F(2,51)=0.10$, $\left.p=.91, \eta_{\mathrm{p}}{ }^{2}=.004\right)$, block x pretreatment $\left(F(2,51)=1.05, p=.357, \eta_{\mathrm{p}}{ }^{2}=.04\right)$, or day x block x pretreatment $\left(F(2,51)=2.69, p=.08, \eta_{\mathrm{p}}^{2}=.10\right)$ interaction effect on distance travelled. As can 
be seen in Figure $1 B$, there was not a main effect of pretreatment on rears, $F(2,51)=0.57, p .57$, $\eta_{\mathrm{p}}^{2}=.02$. There was not a day $\mathrm{x}$ pretreatment $\left(F(2,51)=0.64, p=.53, \eta_{\mathrm{p}}{ }^{2}=.02\right)$, block $\mathrm{x}$ pretreatment $\left(F(2,51)=2.69, p=.077, \eta_{\mathrm{p}}{ }^{2}=.10\right)$, or day x block x pretreatment $(F(2,51)=0.92$, $\left.p=.41, \eta_{\mathrm{p}}^{2}=.04\right)$ interaction effect on rears. As can be seen in Figure $1 C$, there was not a main effect of pretreatment on percent time in the center, $F(2,51)=0.89, p=.42, \eta_{\mathrm{p}}{ }^{2}=.03$. There was not a day x pretreatment $\left(F(2,51)=1.08, p=.35, \eta \mathrm{p}^{2}=.04\right)$, block x pretreatment $(F(2,51)=$ $\left.1.37, p=.26, \eta_{\mathrm{p}}{ }^{2}=.05\right)$, or day x block x pretreatment $\left(F(2,51)=0.29, p=.75, \eta_{\mathrm{p}}{ }^{2}=.01\right)$ interaction effect on percent time in the center.

During the drug challenge in the OF on the first and seventh day, locomotor activities were recorded in 10 min blocks. Distance travelled $(\mathrm{cm})$ in the OF was analyzed across the three pretreatment conditions. As can be seen in Figure 1D, the effect of pretreatment on distance travelled approached significance, $F(2,51)=2.75, p=.07, \eta_{\mathrm{p}}{ }^{2}=.10$. Games-Howell post-hoc test revealed that ACEA pretreated mice $(M=129.95, S E=15.25)$ travelled significantly less distance than vehicle pretreated mice $(M=208.14, S E=23.52), p=.02$. There was not a day $\mathrm{x}$ pretreatment interaction effect (Pillai's trace $=0.02, F(2,51)=0.64, p=.53, \eta_{\mathrm{p}}{ }^{2}=.02$ ) on distance travelled. There was not a block x pretreatment interaction effect (Pillai's trace $=0.32$, $\left.F(16,90)=1.05, p=.41, \eta_{\mathrm{p}}^{2}=.16\right)$ on distance travelled. There was not a day $\mathrm{x}$ block $\mathrm{x}$ pretreatment interaction effect (Pillai's trace $=0.226, F(16,90)=1.47, p=.13, \eta_{\mathrm{p}}{ }^{2}=.21$ ) on distance travelled.

Rearing behavior in the OF was analyzed across the three pretreatment conditions. As can be seen in Figure $1 E$, there was a main effect of pretreatment on rears, $F(2,51)=4.53, p=$ $.02, \eta_{\mathrm{p}}{ }^{2}=.15$. Games-Howell post-hoc test revealed that ACEA pretreated mice $(M=5.50, S E=$ $0.04)$ reared significantly less than vehicle pretreated mice $(M=11.51, S E=0.05), p=.01$. 
There was not a day $\mathrm{x}$ pretreatment interaction effect (Pillai's trace $=0.03, F(2,51)=0.90, p=$ $.41, \eta_{\mathrm{p}}^{2}=.03$ ) on rears. There was not a block x pretreatment interaction effect (Pillai's trace $=$ $\left..03, F(16,90)=1.03, p=.43, \eta_{\mathrm{p}}{ }^{2}=.15\right)$ on rears. There was not a day $\mathrm{x}$ block $\mathrm{x}$ pretreatment interaction effect (Pillai's trace $=0.30, F(16,90)=0.99, p=.48, \eta_{\mathrm{p}}{ }^{2}=.15$ ) on rears.

Percent time in the center was analyzed across the three pretreatment conditions. As can be seen in Figure $1 F$, there was not a main effect of pretreatment on percent time spent in the center, $F(2,51)=2.01, p=.14, \eta_{\mathrm{p}}^{2}=.07$. There was not a day x pretreatment interaction effect (Pillai's trace $=0.07, F(2,51)=1.96, p=.15, \eta_{\mathrm{p}}^{2}=.07$ ) on percent time in center. There was not a block x pretreatment interaction effect (Pillai's trace $=0.18, F(16,90)=0.51, p=.92, \eta_{\mathrm{p}}^{2}=.09$ ) on percent time in center. There was not a day x block x pretreatment interaction effect (Pillai's trace $\left.=0.35, F(16,90)=1.18, p=.30, \eta_{\mathrm{p}}{ }^{2}=.17\right)$ on percent time in center.

\subsubsection{Dopamine Recordings}

Dopamine autoreceptor sensitivity: Autoreceptor sensitivity was analyzed across pretreatment conditions as previously described $[76,78,79]$ As seen in Figure $3 C$, there was not a main effect of drug pretreatment on autoreceptor sensitivity, $F(2,50)=1.66, p=.20, \eta_{\mathrm{p}}{ }^{2}=.06$. There was a significant main effect of amount of pre-pulses on autoreceptor sensitivity, Pillai's trace $=0.77, F(6,45)=25.30, p<.001, \eta_{\mathrm{p}}{ }^{2}=.77$. There was not an amount of pre-pulses $\mathrm{x}$ drug pretreatment interaction effect on autoreceptor sensitivity, Pillai's trace $=0.18, F(12,92)=0.76$, $p=.70, \eta_{\mathrm{p}}^{2}=.09$.

Baseline dopamine release and half-life: Baseline dopamine release $(\mu \mathrm{M})$ and half-life (sec) were assessed across the three pretreatment conditions before administration of the in-test drug challenge. As can be seen in Figure $3 A$ and $B$, there was a significant main effect of drug pretreatment on baseline dopamine release, $F(2,51)=3.21, p=.049, \eta^{2}=.11$. Tukey's post-hoc 
test revealed that mice pretreated with ACEA had decreased dopamine release $(M=0.18, S E=$ $0.03)$ compared to mice pretreated with vehicle $(M=0.29, S E=0.03), p=.04$. No differences were observed between dopamine release of mice pretreated with AA-5-HT $(M=0.26, S E=.03)$ and vehicle, $p=.68$. As can be seen in Figure 3C, baseline dopamine half-life was analyzed across the three pretreatment conditions. There was not a main effect of pretreatment on baseline dopamine half-life, $F(2,51)=0.66, p=.52, \eta^{2}=.02$.

Dopamine recordings following drug challenge (AA-5-HT): During dopamine recordings, a subset of the mice pretreated with AA-5-HT or vehicle received an i.p. drug challenge of either AA-5-HT ( $n=7$ and 6 , respectively per pretreatment) or vehicle $(n=5$ and 4 , respectively per pretreatment). Percent change of dopamine release and half-life (with baseline dopamine release and half-life being 100\%) were analyzed at 10 min intervals for 90 min post injection. As can be seen in Figure 4A, there was not a main effect of AA-5-HT/vehicle pretreatment on percent change in dopamine release, $F(1,19)=0.67, p=.42, \eta_{\mathrm{p}}^{2}=.03$. There was not a main effect of drug challenge (AA-5-HT or vehicle) on percent change in dopamine release, $F(1,19)=0.00024, p=.99, \eta_{\mathrm{p}}^{2}=.00$. There was not a pretreatment $\mathrm{x}$ drug challenge interaction effect $\left(F(1,19)=0.12, p=.73, \eta_{\mathrm{p}}{ }^{2}=.01\right)$ on percent change in dopamine release. There was not a time point $\mathrm{x}$ pretreatment interaction effect (Pillai's trace $=0.57, F(9,11)=1.62$, $\left.p=.22, \eta_{\mathrm{p}}^{2}=.57\right)$ on percent change in dopamine release. There was not a time point $\mathrm{x}$ drug challenge interaction effect (Pillai's trace $=0.45, F(9,11)=0.99, p=.50, \eta_{\mathrm{p}}{ }^{2}=.45$ ) on percent change in dopamine release. There was not a time point $\mathrm{x}$ pretreatment $\mathrm{x}$ drug challenge interaction effect (Pillai's trace $=0.45, F(9,11)=0.23, p=.98, \eta_{\mathrm{p}}{ }^{2}=.16$ ) on percent change in dopamine release. Altogether these data indicate that dopamine release was not altered by AA5-HT injected during recordings, regardless of drug pretreatment. 
Percent change in dopamine half-life was analyzed across pretreatment groups following AA-5-HT or vehicle injections during dopamine recordings. As can be seen in Figure 4B, there was not a main effect of pretreatment on percent change in dopamine half-life, $F(1,19)=0.39, p$ $=.54, \eta_{\mathrm{p}}^{2}=.02$. There was not a main effect of drug challenge on percent change in dopamine half-life, $F(1,19)=3.25, p=.09, \eta_{\mathrm{p}}^{2}=.15$. There was not a pretreatment $\mathrm{x}$ drug challenge interaction effect $\left(F(1,19)=0.10, p=.75, \eta_{\mathrm{p}}^{2}=.01\right)$ on percent change in dopamine half-life. There was not a time point $\mathrm{x}$ pretreatment interaction effect (Pillai's trace $=0.38, F(9,11)=0.75$, $\left.p=.66, \eta_{\mathrm{p}}^{2}=.38\right)$ on percent change in dopamine half-life. There was not a time point $\mathrm{x}$ drug challenge interaction effect (Pillai's trace $=0.39, F(9,11)=0.77, p=.65, \eta_{\mathrm{p}}^{2}=.39$ ) on percent change in dopamine half-life. There was not a time point $\mathrm{x}$ pretreatment $\mathrm{x}$ drug challenge interaction effect (Pillai's trace $=0.60, F(9,11)=1.82, p=.17, \eta_{\mathrm{p}}{ }^{2}=.60$ ) on percent change in dopamine half-life. These data indicate that dopamine half-life was not altered by AA-5-HT injected during recordings, regardless of drug pretreatment.

Dopamine recordings following drug challenge (ACEA): During dopamine recordings, a subset of the mice pretreated with ACEA or vehicle received an i.p. drug challenge of either ACEA ( $n=5$ and 4 , respectively per pretreatment) or vehicle ( $n=5$ and 4 , respectively per pretreatment). Percent change of dopamine release and half-life (with baseline dopamine release and half-life being $100 \%$ ) were analyzed at $10 \mathrm{~min}$ intervals for $90 \mathrm{~min}$ post injection. As can be seen in Figure $4 C$, there was not a main effect of pretreatment on percent change in dopamine release, $F(1,14)=2.09, p=.17, \eta_{\mathrm{p}}^{2}=.13$. The main effect of drug challenge on percent change in dopamine release $\left(F(1,14)=4.59, p=.05, \eta_{\mathrm{p}}{ }^{2}=.25\right)$ approached significance. There was not a pretreatment $\mathrm{x}$ drug challenge interaction effect $\left(F(1,14)=1.55, p=.23, \eta_{\mathrm{p}}{ }^{2}=.10\right)$ on percent change in dopamine release. There was not a time point $\mathrm{x}$ pretreatment effect (Pillai's trace $=$ 
$\left.0.54, F(9,6)=0.79, p=.64, \eta_{\mathrm{p}}^{2}=.54\right)$ on percent change in dopamine release. There was not a time point $\mathrm{x}$ challenge drug interaction (Pillai's trace $=0.78, F(9,6)=2.41, p=.15, \eta_{\mathrm{p}}{ }^{2}=.78$ ) on percent change in dopamine release. There was a time point $\mathrm{x}$ pretreatment $\mathrm{x}$ challenge drug interaction (Pillai's trace $=0.90, F(9,6)=6.07, p=.02, \eta_{\mathrm{p}}{ }^{2}=.90$ ) on percent change in dopamine release. These data indicate that ACEA administration during dopamine recordings attenuated dopamine release to a greater degree in mice pretreated with ACEA.

Percent change in dopamine half-life was analyzed across ACEA and vehicle pretreated mice. As can be seen in Figure 4D, there was not a main effect of pretreatment on percent change in dopamine half-life, $F(1,19)=0.65, p=.44, \eta_{\mathrm{p}}^{2}=.04$. There was not a main effect of drug challenge on percent change in dopamine half-life, $F(1,19)=3.77, p=.073, \eta_{\mathrm{p}}{ }^{2}=.21$. There was not a pretreatment $\mathrm{x}$ drug challenge interaction effect $\left(F(1,19)=0.57, p=.46, \eta_{\mathrm{p}}{ }^{2}=\right.$ .04) on percent change in baseline dopamine half-life. There was not a time point $x$ pretreatment interaction effect (Pillai's trace $=0.60, F(9,6)=1.00, p=.52, \eta_{\mathrm{p}}{ }^{2}=.60$ ) on percent change in baseline dopamine half-life. There was not a time point $\mathrm{x}$ drug challenge interaction effect (Pillai's trace $=0.76, F(9,6)=0.78, p=.19, \eta_{\mathrm{p}}^{2}=.76$ ) on percent change in dopamine half-life. There was not a time point $\mathrm{x}$ pretreatment $\mathrm{x}$ drug challenge interaction effect (Pillai's trace $=$ $\left.0.61, F(9,6)=1.04, p=.50, \eta_{\mathrm{p}}^{2}=.61\right)$ on percent change in baseline dopamine half-life. These data indicate that dopamine half-life was not altered by ACEA injected during recordings, regardless of drug pretreatment.

Dopamine recordings following drug challenge (cocaine): During dopamine recordings, a subset of the mice pretreated with AA-5-HT, ACEA, or vehicle received an i.p. drug challenge of cocaine ( $n=6,5$, and 6 per pretreatment group respectively). Percent change of dopamine release and half-life (with baseline dopamine release being 100\%) was analyzed at $10 \mathrm{~min}$ 
intervals for 60 min post injection. As can be seen in Figure $4 E$, there was not a main effect of pretreatment on percent change in dopamine release, $F(2,14)=1.21, p=.33, \eta_{\mathrm{p}}{ }^{2}=.15$. There was not a time point $\mathrm{x}$ pretreatment interaction effect (Pillai's trace $=0.98, F(12,20)=1.61, p=$ $\left..17, \eta_{\mathrm{p}}^{2}=.49\right)$ on percent change in dopamine release.

Regarding half-life, as can be seen in Figure $4 F$, there was not a main effect of pretreatment on percent change in dopamine half-life, $F(2,14)=2.99, p=.08, \eta_{\mathrm{p}}{ }^{2}=.30$. There was a significant time point $\mathrm{x}$ pretreatment interaction effect (Pillai's trace $=1.20, F(12,20)=$ $\left.2.50, p=.03, \eta_{\mathrm{p}}^{2}=.60\right)$ on percent change in dopamine half-life. There was a near significant main effect of pretreatment (Welch's $\left.F(2,6.68)=4.77, p=.05, \omega^{2}=0.31\right)$ on percent change in dopamine half-life at 10 min post-injection. Games-Howell post-hoc test revealed ACEA pretreated mice's percent change in dopamine half-life following cocaine $(M=273.72, S E=$ 28.11) was significantly increased in comparison to vehicle $(M=170.81, S E=18.43), p=.04$. At 20 min post cocaine, there was a near significant main effect of pretreatment (Welch's $F(2,8.13)=4.42, p=.05$, est. $\left.\omega^{2}=0.29\right)$ on percent change in dopamine half-life. GamesHowell post-hoc test revealed ACEA pretreated mice's percent change in dopamine half-life ( $M$ $=346.19, S E=26.77)$ was significantly increased in comparison to vehicle $(M=240.04, S E=$ 21.68), $p=.04$. No differences in percent change in dopamine half-life were observed between mice pretreated with AA-5-HT $(M=255.06, S E=32.93)$ and vehicle $(M=201.12, S E=25.96)$, $p=.17$. These data indicate that the cocaine drug challenge lead to an increased synaptic halflife for dopamine in all mice but to a greater extent in mice pretreated with ACEA.

Stereotaxic placement of electrodes: As can be seen in Figure $2 A$, following amperometry experiments, the placement of stimulating electrodes $(n=54)$ and recording electrodes $(n=54)$ were determined by examining lesioned regions in sectioned mouse brains. 
The positions of stimulating electrodes were localized within the anatomical region of the VTA spanning -3.08 to $-3.52 \mathrm{~mm}$ AP from bregma and -4.0 to $-5.0 \mathrm{~mm}$ DV from dura, and the positions for the recording electrodes were localized within the anatomical region of the NAc spanning +1.54 to $+1.34 \mathrm{~mm}$ AP from bregma and -4.0 to $-5.0 \mathrm{~mm} \mathrm{DV}$ from dura.

\subsection{Experiment 2 (CPP and Saccharin Preference)}

\subsubsection{Conditioned Place Preference}

The mice did not spend significantly more time on the drug-paired side $(M=911.08 \mathrm{~s}, S E$ $=31.91$ ) than what was to be expected if the chamber was unbiased (i.e., $900 \mathrm{~s}$ for each side), $t(26)=1.62, p=.12$. Time spent on the drug-paired side for day one was subtracted from time spent on the drug-paired side for day eight and as seen in Figure $5 \mathrm{~A}$, there was not a main effect of drug treatment $F(2,26)=2.51, p=.10, \eta^{2}=.17$. Similarly, the number of entries into the drug-paired side for day one was subtracted from the number of entries into the drug-paired side for day eight and as seen in Figure $5 B$, there was not a main effect of drug treatment, $F(2,26)=$ $0.07, p=.94, \eta^{2}=.00$.

Distance travelled was recorded on the conditioning days 2, 4, and 6 when mice were restricted to the drug-paired side of the apparatus and given either an i.p. injection of AA-5-HT, ACEA, or vehicle. As can be seen in Figure 5C, there was not a main effect of drug treatment $\left[F(2,24)=1.36, p=.28, \eta_{\mathrm{p}}^{2}=.10\right]$ or a day $\mathrm{x}$ drug treatment interaction $[F(4,48)=0.74, p=.57$ $\left.\eta_{\mathrm{p}}^{2}=.06\right]$ on distance travelled on drug-paired days.

\subsubsection{Two-Bottle Choice Test}

As can be seen in Figure $6 A$, there was not a main effect of drug treatment on saccharin consumed $\left[\mathrm{g} / \mathrm{kg}\right.$ body weight; $\left.F(2,24)=0.18, p=.83, \eta_{\mathrm{p}}{ }^{2}=.02\right]$, nor was there a significant day $\mathrm{x}$ drug treatment interaction $\left[F(8,44)=0.54, p=.82, \mathrm{n}_{\mathrm{p}}{ }^{2}=.09\right]$. Additionally, as can be seen in 
Figure $6 B$, there was not a significant main effect of drug treatment $\left[F(2,24)=0.004, p=.99, \eta_{\mathrm{p}}^{2}\right.$

$=.00]$, or a significant day $\mathrm{x}$ drug treatment interaction $\left(F(8,96)=0.68, p=.71, \mathrm{\eta}_{\mathrm{p}}^{2}=.05\right)$ on saccharin preference.

\section{Discussion}

The cannabinergic system is a target for the development of potential anxiolytic drugs. The mesolimbic dopamine pathway plays integral roles in addiction and anxiety. Therefore, the development of anxiolytic pharmaceuticals necessitates exploring the dopaminergic alterations in response to their administration. The current study aimed to explore the addictive potential of indirectly or directly modulating cannabinergic signaling via AA-5-HT or ACEA administration, respectively.

\subsection{Experiment 1 (Locomotor Activity and Dopamine Release)}

In the OF, AA-5-HT administration did not significantly alter locomotor activities including distance travelled, rearing, or percent time in the center. The lack of change in distance travelled and rearing may be indicative of a non-addictive profile for this drug. Previous research has shown that $\mathrm{AA}-5-\mathrm{HT}$ and $\mathrm{AACOCF}_{3}$ (an FAAH inhibitor) did not alter locomotor activity in the OF $[27,82]$. However, with no change in percent time in center, this drug also did not appear to have anxiolytic potential in this study. This may have occurred due to the choice of strain (B6) over a more anxious strain and due to the choice of test for anxiety as moderate anxiolytic effects were found in BALB/cJ mice and in the EPM [27,40]. Further research could explore the anxiolytic potential of this drug in more anxious mice or more anxiogenic tests. ACEA significantly decreased the rearing frequency of mice but did not alter distance travelled or percent time in center. Similarly, previous research has shown that $\mathrm{CB}_{1} \mathrm{R}$ agonists do not alter 
locomotor activities in the OF except for suppressing rearing behavior $[27,82,83]$. Future research could address the length of the OF test as it may have been too long as the mice moved infrequently between 70 and 90 mins in the OF. This time-induced floor effect may have masked drug-effects. An altered paradigm such as a shorter OF test or altered design such as the EPM or forced swim test may reveal anxiolytic effects. However, the mouse strain and OF contexts of the current study did not provide behaviors related to anxiety or addiction.

Regarding dopamine release recordings using in vivo fixed potential amperometry, chronic pretreatment of AA-5-HT did not significantly alter dopamine dynamics at baseline, in autoreceptor sensitivity, or following drug challenge (vehicle, AA-5-HT, or cocaine). Previous research has shown an acute injection of AA-5-HT to attenuate evoked dopamine release [27], but these findings were not repeated in the current study. Both studies, however, support a lack of reinforcing effects of AA-5-HT administration via not increasing dopamine in the NAc, which coincides with previous studies exploring FAAH inhibition [27,84-87]. AA-5-HT pretreatment did not alter dopamine dynamics in response to a cocaine drug challenge during amperometric recordings. Inhibition of FAAH has been shown to enhance [61] effects of cocaine and decrease [58] effects of d-amphetamine sensitization, with differences between these findings likely related to dosing regimens and drug action. Furthermore, inhibition of FAAH did not alter cocaine self-administration but did reduce cue-induced drug-seeking behaviors [88]. Altogether these studies suggest that this indirect means of altering the cannabinoid system via FAAH inhibition does not consistently influence the reward system, especially in a direction associated with abuse and addiction.

Chronic pretreatment of the direct $\mathrm{CB}_{1} \mathrm{R}$ agonist ACEA significantly reduced baseline dopamine release and increased the dopaminergic response to the drug challenges (ACEA and 
cocaine) during amperometry. A previous study from our laboratory found acute ACEA administration attenuated evoked dopamine release in the NAc [27]. Additional studies found similar results utilizing other direct $\mathrm{CB}_{1} \mathrm{R}$ agonists and fast-scan cyclic voltammetry (FSCV), a similar technique measuring subsecond dopamine transmission $[60,64]$. These previous findings were expanded upon in the current study, showing that ACEA-induced attenuation of dopamine release is magnified by repeated exposure to ACEA. ACEA-induced changes in dopamine release does not seem to be related to changes in autoreceptor functioning or DAT efficiency. DAT efficiency can be compared by measurements of the synaptic half-life of stimulationevoked dopamine $[60,64]$. Mice pretreated with ACEA and/or administered ACEA during dopamine recordings displayed comparable dopamine synaptic half-life measurements relative to mice that received vehicle. Similarly, administration of the $\mathrm{CB}_{1} \mathrm{R}$ agonist WIN55,212-2 did not alter synaptic clearance of NAc dopamine as measured with FSCV [64]; however, when measured in the striatum with chronoamperometry over the span of minutes rather than subseconds, dopamine clearance rates were decreased by administration of WIN55,212-2 [89]. Additionally, chronic, 20-day administration of WIN55,212-2 reduced DAT protein levels in the striatum and DAT mRNA levels and binding in the VTA [90]. Thus, differing results are likely due to quantification technique, brain area examined, and/or dosing regimens. Similar to the indirect cannabinoid agonist AA-5-HT, the direct $\mathrm{CB}_{1} \mathrm{R}$ agonist $\mathrm{ACEA}$ also does not elicit a dopaminergic profile associated with abuse and addiction. ACEA did, however, alter dopamine transmission in a way that may have primed the system to respond differently to other dopamine modulating drugs of abuse.

In the current study, pretreatment with the direct $\mathrm{CB}_{1} \mathrm{R}$ agonist $\mathrm{ACEA}$ increased the dopaminergic response (percent change in dopamine half-life) following cocaine. Similarly, 
$\mathrm{CB}_{1} \mathrm{R}$ antagonism decreased cocaine-induced dopamine transient frequency and amplitude in the

NAc in a 2-AG-dependent manner, suggesting an eCB- and $\mathrm{CB}_{1} \mathrm{R}$-dependent inhibition of dopamine signaling $[91,92]$, and the $\mathrm{CB}_{1} \mathrm{R}$ antagonist rimonabant attenuated dopamine release produced via cocaine sensitization in the NAc core [61]. These findings support behavioral studies in which $\mathrm{CB}_{1} \mathrm{R}$ agonists increase behavioral effects of psychostimulants $(93,94)$. However, it should be noted that other studies have shown the opposite, $\mathrm{CB}_{1} \mathrm{R}$ agonists causing reduced behavioral effects of psychostimulants $[95,96]$. Repeated exposure to $\mathrm{CB}_{1} \mathrm{R}$ agonists is likely altering neurotransmission in other areas, which is potentially influencing anxiety and memory-consolidation $[27,96]$ in ways that may overpower the behavioral effects of these dopaminergic changes. Studies in which these drug-induced dopaminergic changes are monitored in behaving animals are needed to elucidate their direct role in mediated rewardrelated behaviors. Nonetheless, the direct $\mathrm{CB}_{1} \mathrm{R}$ agonist $\mathrm{ACEA}$ decreased baseline dopamine release and altered the dopaminergic response to cocaine, indicating that chronic administration of direct $\mathrm{CB}_{1} \mathrm{R}$ agonists may interfere with the efficacy of other drugs that act on the dopamine system such as amphetamines that bind to and reverse DAT function and alter DAT trafficking [97].

\subsection{Experiment 2 (CPP and Saccharin Preference)}

During CPP, mice did not develop a CPP or CPA for either AA-5-HT or ACEA.

Previous research has shown that Wistar rats, Sprague-Dawley rats, and B6 mice in standard housing conditions do not have a CPP for AM404, AM404 except at $10.0 \mathrm{mg} / \mathrm{kg}$, or SBFI26 (an inhibitor of FABP5 and FABP7) respectively [98-100]. Direct $\mathrm{CB}_{1} \mathrm{R}$ agonist administration can produce CPP, no preference, or CPA in a drug and dose-dependent manner where THC typically causes a CPP under $5.0 \mathrm{mg} / \mathrm{kg}$ and a CPA at $5.0 \mathrm{mg} / \mathrm{kg}$ or higher but WIN55,212-2 has variable 
results where a CPP occurred under $1.0 \mathrm{mg} / \mathrm{kg}$, no preference occurred from $1.0 \mathrm{mg} / \mathrm{kg}$ to 3.0 $\mathrm{mg} / \mathrm{kg}$, and a CPA occurred from $0.25 \mathrm{mg} / \mathrm{kg}$ to $2.5 \mathrm{mg} / \mathrm{kg}[101,102]$. Therefore, indirectly and directly agonizing the cannabinergic system can lead to CPP, but the doses in the current study, which were chosen due to their anxiolytic potential, did not, which suggests these doses are not rewarding or aversive in the current paradigm.

During the two-bottle choice test, mice treated with either AA-5-HT or ACEA did not develop a preference or aversion for saccharin. CP 55,940 (direct cannabinoid agonist), URB597, and rimonabant had no effects on saccharin preference alone, but chronic mild stressinduced reductions in sucrose preference were attenuated by CP 55,940 or URB597 and enhanced by rimonabant $[103,104]$. This suggests that indirectly and directly agonizing the cannabinoid system does not alter preference for sweet rewards alone but can modify stressinduced alterations in preference. Therefore, exploring preference for saccharin following both cannabinoid administration and stress may further the potential use of these drugs as anxiolytics. However, CP 55,940 increased progressive ratio responding for Ensure where rimonabant reduced it, suggesting the cannabinergic system still plays a role in the wanting of sweet rewards [105]. AA-5-HT and ACEA administration did not alter saccharin preference, indicating these drugs do not elicit reward- or anhedonia-related behaviors.

\subsection{Cross-Modulation of the Cannabinergic and Dopaminergic Systems}

Cross-modulation between neurotransmission systems can impact the efficacy and offtarget effects of posited drugs. The current study explored the interplay between the cannabinergic system and dopaminergic system through chronic administration of the indirect cannabinoid agonist AA-5-HT and the direct $\mathrm{CB}_{1} \mathrm{R}$ agonist ACEA. AA-5-HT did not modulate mesolimbic dopamine neurotransmission, but ACEA decreased baseline dopamine release, both 
acutely and chronically, and enhanced cocaine-induced increases in dopamine half-life in the NAc. Cannabinoid induced increases in DRs and decreases in $\mathrm{CB}_{1}$ Rs could lead to a system primed for dysregulation and super-sensitization of the dopamine system due to increasing DR populations and decreasing $\mathrm{GABA}_{\mathrm{A}} \mathrm{R}$ modulation, which could prime the brain, especially the mesolimbic dopamine pathway for addiction to drugs that act on this pathway $[62,106]$. The current study indicates this potential via enhanced cocaine-induced dopamine-half in the NAc following ACEA pretreatment. It should be noted that the current study was conducted in adult mice. Previous behavioral studies have shown that cannabinoid agonists administered during adolescence enhance the reinforcing effects of cocaine to a greater degree than those administered in adulthood $[107,108]$. These drugs as well as other pharmaceuticals affecting the cannabinergic and dopaminergic systems must be monitored to prevent deleterious off-target and side effects.

The cannabinergic system remains a target for the development of anxiolytic pharmaceuticals. Given that ACEA decreased NAc dopamine release and potentiated the dopaminergic effect of a psychostimulant while AA-5-HT had no effect on NAc dopamine release, indirect mechanisms of agonizing the cannabinoid system may be a better alternative than direct mechanisms if concerned with disrupting dopamine function. Still, neither drug increased NAc dopamine release, altered locomotor activity in the OF, induced CPP, or altered saccharin preference. Thus, the current study did not find an abuse potential from indirectly or directly agonizing the cannabinergic system and suggests, with future research, that the cannabinergic system may still be a potential target for the treatment of anxiety. 


\section{References}

[1] American Psychiatric Association. (2013a). Anxiety disorders. In Diagnostic and statistical manual of mental disorders (5th ed.). doi:10.1176/appi.books.9780890425596.dsm05

[2] Brosschot, J.F., Verkuil B., \& Thayer, J.F. (2016). The default response to uncertainty and the importance of perceived safety in anxiety and stress: An evolution-theoretical perspective. Journal of Anxiety Disorders, 41, 22-34. doi:10.1016/j.janxdis.2016.04.012

[3] Kessler, R.C. Chiu, W.T., Demler, O., Walters, E.E. (2005). Prevalence, severity, and comorbidity of 12-month dsm-iv disorders in the national comorbidity survey replication. Archives of General Psychiatry, 62(6), 617-627. doi:10.1001/archpsyc.62.6.617

[4] Shrineshan, E., Bailey, J., Relyea, G., Franklin, B.E., Solomon, D.K., \& Brown, L.M. (2013). Incremental direct medical expenditures associated with anxiety disorders for the U.S. adult population: Evidence from medical expenditure panel survey. Journal of Anxiety Disorders, 72(7), 720-727. doi:10.1016/j.janxdis.2013.09.009

[5] Bachhuber, M.A., Hennessy, S., Cunningham, C.O., \& Starrels, J. (2016). Increasing benzodiazepine prescriptions and overdose mortality in the United States, 1996-2013. American Journal of Public Health, 106(4), 686-688. doi:10.2105/AJPH.2016.303061

[6] Braestrup, C. \& Squires, R.F. (1977). Specific benzodiazepine receptors in rat brain characterized by high-affinity $(3 \mathrm{H})$ diazepam binding. Proceedings of the National Academy of Sciences of the United States of America, 74(9), 3805-3809. doi:10.1073/pnas.74.9.3805

[7] Heikkinen, A.E., Möykkynen, T.P., \& Korpi, E.R. (2009). Long-lasting modulation of glutamatergic transmission in VTA dopamine neurons after a single dose of benzodiazepine agonists. Neuropsychopharmacology, 34(2), 290-298. doi:10.1038/npp.2008.89

[8] Farach, F.J., Pruitt, L.D., Jun, J.J., Jerud, A.B., Zoellner, L.A., \& Roy-Byrne, P.P. (2012). Pharmacological treatment of anxiety disorders: Current treatments and future directions. Journal of Anxiety Disorders, 26(8), 833-843. doi:10.1016/j.janxdis.2012.07.009

[9] Gollan, J.K., Fava, M., Kurian, B., Wisniewski, S.R., Rush, A.J., Daly, E.,...Trivedi, M.H. (2012). What are the clinical implications of new onset or worsening anxiety during the first two weeks of SSRI treatment for depression? Depression and Anxiety, 29(2), 94101. doi:10.1002/da.20917

[10] Montgomery, S.A., Sheehan, D.V., Meoni, P., Haudiquet, V., \& Hackett, D. (2002). Characterization of the longitudinal course of improvement in generalized anxiety disorder during long-term treatment with venlafaxine XR. Journal of Psychiatric Research, 36(4), 209-217. doi:10.1016/S0022-3956(02)00005-5 
[11] Tan, K.R., Brown, M., Labouèbe, G., Yvon, C., Creton, C., Fritschy, J.,...Lüscher, C. (2010). Neural basis for addictive properties of benzodiazepines. Nature, 463(7282), 769774. doi:10.1038/nature08758

[12] Howlett, A.C., Barth, F., Bonner, T.I., Cabral, G., Casellas, P., Devane, W.A.,.. Pertwee, R.G. (2002). International union of pharmacology. Xxvii. Classification of cannabinoid receptors. Pharmacological Reviews, 54(2), 161-202. doi:10.1124/pr.54.2.161

[13] Kano, M., Ohno-Shosaku, T., Hashimotodani, Y., Uchigashima, M., \& Watanabe, M. (2009). Endocannabinoid-mediated control of synaptic transmission. Physiological Review, 89(1), 309-380. doi:10.1152/physrev.00019.2008

[14] Katona, I., Sperlágh, B., Sík, A., Käfalvi, A., Vizi, E.S., Mackie, K., \& Freund, T.F. (1999). Presynaptically located CB1 cannabinoid receptors regulate GABA release from axon terminals of specific hippocampal neurons. The Journal of Neuroscience, 19(1), 45444558. doi:10.1523/JNEUROSCI.19-11-04544.1999

[15] Rubino, T., Guidali, C., Vigano, D., Realini, N., Valenti, M., Massi, P., \& Parolaro, D. (2008). $\mathrm{CB}_{1}$ receptor stimulation in specific brain areas differently modulate anxietyrelated behavior. Neuropsychopharmacology, 54(1), 151-160.

doi:10.1016/j.neuropharm.2007.06.024

[16] Batista, L.A., Gobira, P.H., Viana, T.G., Aguiar, D.C., \& Moreira, F.A. (2014). Inhibition of endocannabinoid neuronal uptake and hydrolysis as strategies for developing anxiolytic drugs. Behavioural Pharmacology, 25(5-6), 425-433. doi:10.1097/FBP.0000000000000073

[17] Blankman, J.L. \& Cravatt, B.F. (2013). Chemical probes of endocannabinoid metabolism. Pharmacological Reviews, 65(2), 849-871. doi:10.1124/pr.112.006387

[18] Dinh, T.P., Carpenter, D., Leslie, F.M., Freund, T.F., Katona, I., Sensi, S.L.,...Piomelli, D. (2002). Brain monoglyceride lipase participating in endocannabinoid inactivation. Proceedings of the National Academy of Sciences of the United States of America, 99(16), 10819-10824. doi:10.1073/pnas.152334899

[19] Giang, D.K. \& Cravatt, B.F. (1997). Molecular characterization of human and mouse fatty amide hydrolases. Proceedings of the National Academy of Sciences of the United States of America, 94(6), 2238-2242. doi:10.1073/pnas.94.6.2238

[20] Gulyas, A.I., Cravatt, B.F., Bracey, M.H., Dinh, T.P., Piomelli, D., Boscia, F., \& Freund, T.F. (2004). Segregation of two endocannabinoid-hydrolyzing enzymes into pre- and postsynaptic compartments in the rat hippocampus, cerebellum, and amygdala. The European Journal of Neuroscience, 20(2), 441-458. doi:10.1111/j.14609568.2004.03428.x 
[21] Haj-Dahmane, S., Shen, R., Elmes, M.W., Studholme, K., Kanjiya, M.P., Bodgan, D.,...Kaczocha, M. (2018). Fatty-acid-binding protein 5 controls retrograde cannabinoid signaling at central glutamate synapses. Proceedings of the National Academy of Sciences of the United States of America, 115(3), 3482-3487. doi:10.1073/pnas.1721339115

[22] Kaczocha, M., Glaser, S.T., \& Deutsch, D.G. (2009). Identification of intracellular carriers for the endocannabinoid anandamide. Proceedings of the National Academy of Sciences of the United States of America, 106(15), 6375-6380. doi:10.1073/pnas.0901515106

[23] Ohno-Shosaku, T., Maejima, T., \& Kano, M. (2001). Endogenous cannabinoids mediate retrograde signals from depolarized postsynaptic neurons to presynaptic terminals. Neuron, 29(3), 729-738. doi:10.1016/S0896-6273(01)00247-1

[24] Maccarrone, M. (2017). Metabolism of the endocannabinoid anandamide: Open questions after 25 years. Frontiers in Molecular Neuroscience, 10, 166, doi:10.3389/fnmol.2017.00166

[25] Maione, S., De Petrocellis, L., de Novellis, V., Moriello, A.S., Petrosino, S., Palazzo, E.,...Di Marzo, V. (2007) Analgesic actions of $N$-arachidonoyl-serotonin, a fatty acid amide hydrolase inhibitor with antagonistic activity at vanilloid TRPV1 receptors. British Journal of Pharmacology, 150(6), 766-781. doi:10.1038/sj.bjp.0707145

[26] Fogaça, M.V., Aguiar, D.C., Moreira, F.A., Guimarães, F.S. (2012). The endocannabinoid and endovanilloid systems interact in the rat prelimbic medial prefrontal cortex to control anxiety-like behavior. Neuropharmacology, 63(2), 202-210. doi:10.1016/j.neuropharm.2012.03.007

[27] Freels, T.F., Lester, D.B., \& Cook, M.N. (2019). Arachidonoyl serotonin (AA-5-HT) modulates general fear-like behavior and inhibits mesolimbic dopamine release. Behavioural Brain Research, 362, 140-151. doi:10.1016/j.bbr.2019.01.010

[28] Hakimizadeh, E., Oryan, S., Moghaddam, A.H., Shamsizadeh, A., \& Roohbakhsh, A. (2012). Endocannabinoid system and trpv1 receptors in the dorsal hippocampus of the rats modulate anxiety-like behaviors. Iranian Journal of Basic Medical Sciences, 15(3), 795-802. doi:10.22038/ijbms.2012.4863

[29] Zaitone, S.A., El-Wakeil, A.F., \& Abou-El-Ela, S.H. (2012). Inhibition of fatty acid amide hydrolase by URB597 attenuates the anxiolytic-like effect of acetaminophen in the mouse elevated plus-maze test. Behavioural Pharmacology, 23(4), 417-425. doi:10.1097/FBP.0b013e3283566065

[30] Patel, S. \& Hillard, C.J. (2006). Pharmacological evaluation of cannabinoid receptor ligands in a mouse model of anxiety: Further evidence of an anxiolytic role for endogenous cannabinoid signaling. The Journal of Pharmacology and Experimental Therapeutics, 318(1), 304-311. doi:10.1124/jpet.106.101287 
[31] Rey, A.A., Purrio, M., Viveros, M.P., \& Lutz, B. (2012) Biphasic effects of cannabinoids in anxiety responses: $\mathrm{CB} 1$ and $\mathrm{GABA}(\mathrm{B})$ receptors in the balance of GABAergic and glutamatergic neurotransmission. Neuropsychopharmacology, 37(12), 2624-234. doi:10.1038/npp.2012.123

[32] Aguiar, D.C., Terzian, A.L., Guimarães, F.S., \& Moreira, F.A. (2009). Anxiolytic-like effects induced by blockade of transient receptor vanilloid type 1 (TRPV1) channels in the medial prefrontal cortex of rats. Psychopharmacology, 205(2), 217-225. doi:10.1007/s00213-009-1532-5

[33] Terzian, A.L., Aguiar, D.C., Guimarães, F.S., Moreira, F.A. (2009). Modulation of anxietylike behavior by transient receptor potential vanilloid type $1\left(\mathrm{TRPV}_{1}\right)$ channels located in the dorsolateral periaqueductal gray. European Neuropsychopharmacology, 19(3), 188195. doi:10.1016/j.euroneuro.2008.11.004

[34] Marsch, R., Foeller, E., Rammes, G., Bunck, M., Kössl, M., Holsboer, F.,...Wotjack, C.T. (2007). Reduced anxiety, conditioned fear, and hippocampal long-term potentiation in transient receptor potential type 1 receptor-deficient mice. The Journal of Neuroscience, 27(4), 832-839. doi:10.1523/JNEUROSCI.3303-06.2007

[35] De Petrocellis, L., Bisogno, T., Maccarrone, M., Davis, J.B., Finazzi-Agro, A., \& Di Marzo, V. (2001). The activity of anandamide at vanilloid VR1 receptors requires facilitated transport across the cell membrane and is limited by intracellular metabolism. The Journal of Biological Chemistry, 276(16), 12856-12863. doi:10.1074/jbc.M008555200

[36] Kaur, J.A. \& Gibson, H.E. (2009). Hot flash: TRPV channels in the brain. Trends in Neurosciences, 32(4), 215-224. doi:10.1016/j.tins.2008.12.006

[37] Smart, D., Gunthorpe, M.J., Jerman, J.C., Nasir, S., Gray, J., Muir, A.I.,...Davis, J.B. (2000). The endogenous lipid anandamide is a full agonist at the human vanilloid receptor $\left(\mathrm{hVR}_{1}\right)$. British Journal of Pharmacology, 129(2), 227-230. doi:10.1038/sj.bjp.0703050

[38] Rosenbaum, T. \& Simon, S.A. (2007). TRPV 1 receptors and signal transduction. In, W.B. Liedtke \& Heller S. (Eds.) TRP ion channel function in sensory transduction and cellular signaling cascades (pp. 69-85). Boca Raton, FL: CRC Press: Taylor and Francis Group.

[39] Ross, R.A. (2003). Anandamide and vanilloid TRPV1 receptors. British Journal of Pharmacology, 140(5), 790-801. doi:10.1038/sj.bjp.0705467

[40] Micale, V., Cristino, L. Tamburella, A., Petrosino, S., Leggio, G.M., Drago, F., \& Di Marzo, V. (2009). Anxiolytic effects in mice of a dual blocker of fatty acid amide hydrolase and transient receptor potential type-1 channels. Neuropsychopharmacology, 34(3), 593-606. doi:10.1038/npp.2008.98 
[41] Casarotto, P.C., Terzian, A.L., Aguiar, D.C., Zangrossi, H., Guimarães, F.S., Wotjak, C.T., \& Moreira, F.A. (2012). Opposing roles for cannabinoid receptor type-1 (cb1) and transient receptor potential vanilloid type-1 channel (trpv1) on the modulation of paniclike responses in rats. Neuropsychopharmacology, 37(2), 478-486.

doi:10.1038/npp.2011.207

[42] John, C.S. \& Currie, P.J. (2012). N-arachidonoyl-serotonin in the basolateral amygdala increases anxiolytic behavior in the elevated plus maze. Behavioural Brain Research, 233(2), 382-388. doi:10.1016/j.bbr.2012.05.025

[43] Price, T.J., Patwardhan, A., Akopian, A.N., Hargreaves, K.M., \& Flores, C.M. (2004). Cannabinoid receptor-independent actions of the aminoalkylindole WIN 55,212-2 on trigeminal sensory neurons. British Journal of Pharmacology, 142(2), 257-266. doi:10.1038/sj.bjp.0705778

[44] Rutkowska, M. \& Jachimczuk, O. (2004). Antidepressant-like properties of ACEA (arachidinoyl-2-chloroethylamide), the selective agonist of CB1 receptors. Acta Poloniea Pharmaceutica - Drug Research, 61(2), 165-167.

[45] Simone, J.J., Malivoire, B.L., \& McCormick, C.M. (2015). Effects of CB1 receptor agonism and antagonism on behavioral fear and physiological stress responses in adult intact, ovariectomized, and estradiol-replaced female rats. Neuroscience, 306, 123-137. doi:10.1016/j.neuroscience.2015.08.032

[46] Neve, K.A., Seamans, J.K., \& Trantham-Davidson, H. (2004). Dopamine receptor signaling. Journal of Receptor and Signal Transduction Research, 24(3), 165-205. doi:10.1081/RRS-200029981

[47] Stoof, J.C. \& Kebabian, J.W. (1981). Opposing roles of D-1 and D-2 dopamine receptors in efflux of cyclic AMP from rat neostriatum. Nature, 294(5839), 366-368. doi:10.1038/294366a0

[48] Usiello, A., Baik, J.H., Rougé-Pont, F., Picetti, R., Dierich, A., LeMeur, M., Piazza, P.V., \& Borrelli, E. (2000). Distinct functions of the two isoforms of dopamine D2 receptors. Nature, 408(6808), 199-203, doi:10.1038/35041572

[49] Torres, G.E., Gainetdinov, R.R., Caron, M.G. (2003). Plasma membrane monoamine transporters: Structure, regulation and function. Nature Reviews Neuroscience, 4(1), 1325. doi:10.1038/nrn1008

[50] Berridge, K.C. \& Robinson, T.E. (1998). What is the role of dopamine in reward: Hedonic impact, reward learning, or incentive salience? Brain Research Reviews, 28(3), 309-369. doi:10.1016/S0165-0173(98)00019-8 
[51] Day, J.J., Roitman, M.F., Wightman, R.M., \& Carelli, R.M. (2007). Associative learning mediates dynamic shifts in dopamine signaling in the nucleus accumbens. Nature Neuroscience, 10(8), 1020-1028. doi:10.1038/nn1923

[52] Everitt, B.J. \& Robbins, T.W. (2005). Neural systems of reinforcement for drug addiction: From actions, to habits, to compulsion. Nature Neuroscience, 8, 1481-1489. doi:10.1038/nn1579

[53] Saal, D., Dong, Y., Bonci, A., \& Malenka, R.C. (2003). Drugs of abuse and stress trigger a common synaptic adaption in dopamine neurons. Neuron, 37, 577-582. doi:10.1016/S0896-6273(03)00021-7

[54] Chen, J.P. Paredes, W., Li, Y., Smith, D., Lowinson, J., \& Gardner, E.L. (1990). Delta 9tetrahydrocannabinol produces naloxone-blockable enhancement of presynaptic basal dopamine efflux in the nucleus accumbens of conscious, freely-moving rats as measured by intracerebral microdialysis. Psychopharmacology, 102(2). doi:10.1007/BF02245916

[55] Gardner, E.L. (2011). Introduction: Addiction and brain reward and anti-reward pathways. Advances in Psychosomatic Medicine, 30, 22-60. doi:10.1159/000324065

[56] Solinas, M., Justinová, Z., Goldberg, S.R., \& Tanda, G. (2006). Anandamide administration alone and after inhibition of fatty acid amide hydrolase (FAAH) increases dopamine in the nucleus accumbens shell in rats. Journal of Neurochemistry, 98(2), 408-419. doi:10.1111/j.1471-4159.2006.03880.x

[57] Vlachou, S., Stamatopoulou, F., Nomikos, G.G., \& Panagis, G. (2008). Enhancement of endocannabinoid neurotransmission through $\mathrm{CB}_{1}$ cannabinoid receptors counteracts the reinforcing and psychostimulant effects of cocaine. International Journal of Neuropsychopharmacology, 11(7), 905-923. doi:10.1017/S1461145708008717

[58] Eisenstein, S.A., Holmes, P.V., \& Hohmann, A.G. (2009). Endocannabinoid modulation of amphetamine sensitization is disrupted in a rodent model of lesion-induced dopamine dysregulation. Synapse, 63(11), 941-950. doi:10.1002/syn.20679

[59] Luque-Rojas, M.J., Galeano, P., Suárez, J., Araos, P., Santín, L.J., de Fonseca, F.R., \& Calvo, E.B. (2013). Hyperactivity induced by dopamine D2/D3 receptor agonist quinpirole is attenuated by inhibitors of endocannabinoid degradation in mice. The International Journal of Neuropsychopharmacology, 16(3), 661-676. doi:10.1017/S1461145712000569

[60] O’Neill, C., Evers-Donnelly, A., Nicholson, D., O’Boyle, K. M., \& O’Connor, J. J. (2009). D2 receptor-mediated inhibition of dopamine release in the rat striatum in vitro is modulated by cb1 receptors: Studies using fast cyclic voltammetry. The Journal of Neurochemistry, 108(3), 545-551. doi:10.1111/j.1471-4159.2008.05782.x 
[61] Mereu, M., Tronci, V., Chun, L.E., Thomas, A.M., Green, J.L., Katz, J.L., \& Tanda G. (2013). Cocaine-induced endocannabinoid release modulates behavioral and neurochemical sensitization in mice. Addiction Biology, 20(1), 91-103. doi:10.1111/adb. 12080

[62] Ginovart, N., Tournier, B.B., Moulin-Shallanon, M., Steimer, T., Ibanez, V., \& Millet, P. (2012). Chronic $\Delta^{9}$-tetrahydracannabinol exposure induces a sensitization of dopamine $\mathrm{D}_{2 / 3}$ receptors in the mesoaccumbens and nigrostriatal systems.

Neuropsychopharmacology, 37(11), 2355-2367. doi:10.1038/npp.2012.91

[63] Cadoni, C., Valentini, V., \& Di Chiara, G. (2008). Behavioral sensitization to $\Delta 9$ tetrahydrocannabinol and cross-sensitization with morphine: Differential changes in accumbal shell and core dopamine transmission. Journal of Neurochemistry, 106(4), 1586-1593. doi:10.1111/j.1471-4159.2008.05503.x

[64] Cheer, J.F., Wassum, K.M., Heien, M.L., Phillips, P.E., \& Wightman, R.M. (2004). Cannabinoids enhance subsecond dopamine release in the nucleus accumbens of awake rats. The Journal of Neuroscience, 24(18), 4393-4400. doi:10.1523/JNEUROSCI.052904.2004

[65] Cortright, J.J., Lorrain, D.S., Beeler, J.A., Tang, W.-J., \& Vezina, P. (2011). Previous exposure to $\Delta 9$-tetrahydracannabinol enhances locomotor responding to but not selfadministration of amphetamine. The Journal of Pharmacology and Experimental Therapeutics, 337(3), 724-733. doi:10.1124/jpet.111.180208

[66] American Psychiatric Association. (2013b). Depressive disorders. In Diagnostic and statistical manual of mental disorders ( $5^{\text {th }} \mathrm{ed}$.). doi:10.1176/appi.books.9780890425596.dsm04

[67] Liu, M.Y., Yin, C.Y., Zhu, L.J., Zhu, X.H., Xu, C., Luo, C.X.,...Zhou, G.Q. (2018). Sucrose preference test for measurement of stress-induced anhedonia in mice. Nature Protocols, 13, 1686-1698. doi:10.1038/s41596-018-0011-z

[68] Sheffield, F.D. \& Roby, T.B. (1950). Reward value of a non-nutritive sweet taste. Journal of Comparative and Physiological Psychology, 43(6), 471-481. doi:10.1037/h0061365

[69] Terzian, A. L., Drago, F., Wotjak, C. T., \& Micale, V. (2011). The dopamine and cannabinoid interaction in the modulation of emotions and cognition: Assessing the role of cannabinoid CB1 receptor in neurons expressing dopamine D1 receptors. Frontiers in Behavioral Neuroscience, 5, 49. doi:10.3389/fnbeh.2011.00049

[70] Barrus, D.G., Lefever, T.W., \& Wiley, J.L. (2018). Evaluation of reinforcing and aversive effects of voluntary $\Delta^{9}$-tetrahydracannabinol ingestion in rats. Neuropharmacology, 137, 133-140. doi:10.1016/j.neuropharm.2018.04.018 
[71] Hempel, B.J., Wakeford, A.G.P., Clasen, M.M., Friar, M.A., \& Riley, A.L. (2016). Delta-9tetrahydrocannabinol (THC) history fails to affect THC's ability to induce place preferences in rats. Pharmacology, Biochemistry and Behavior, 144, 1-6. doi:10.1016/j.pbb.2016.02.007

[72] Parker, L.A. \& Gillies, T. (1995). THC-induced place and taste aversions in lewis and sprague-dawley rats. Behavioral Neuroscience, 109(1), 71-78. doi:10.1037//07357044.109.1.71

[73] Stuber, G. D., Sparta, D. R., Stamatakis, A. M., van Leeuwen, W. A., Hardjoprajitno, J. E., Cho, S., Tye, K. M., Kempadoo, K. A., Zhang, F., Deisseroth, K., \& Bonci, A. (2011). Excitatory transmission from the amygdala to nucleus accumbens facilitates reward seeking. Nature, 475(7356), 377-380. doi:10.1038/nature10194

[74] Paxinos, G. \& Franklin, K.B. (2001). The mouse brain in stereotaxic coordinates (2 ${ }^{\text {nd }}$ ed.). San Diego, CA: Academic Press.

[75] Dugast, C. Suaud-Chagny, M.F., \& Gonon, F. (1994). Continuous in vivo monitoring of evoked dopamine release in the rat nucleus accumbens by amperometry. Neuroscience, 62(3), 647-654. doi:10.1016/0306-4522(94)90466-9

[76] Holloway, Z., Freels, T.F., Comstock, J.F., Nolen, H.G., Sable, H.J. \& Lester, D.B. (2018). Comparing phasic dopamine dynamics in the striatum, nucleus accumbens, amygdala, and medial prefrontal cortex. Synapse, 73(2). doi:10.1002/syn.22074

[77] Prater, W.T., Swamy, M., Beane, M.D., \& Lester, D.B. (2018). Examining the effects of common laboratory methods on the sensitivity of carbon fiber electrodes in amperometric recordings of dopamine. Journal of Behavioral and Brain Science, 8(3), 117-125. doi:10.4236/jbbs.2018.83007

[78] Fielding, J.R., Rogers, T.D., Meyers, A.E., Miller, M.M., Nelms, J.L., Mittleman, G., Blaha, C.D., \& Sable, H.J. (2013). Stimulation-evoked dopamine release in the nucleus accumbens following cocaine administration in rats perinatally exposed to polychlorinated biphenyls. Toxicology Sciences, 136(1), 144-153. doi:10.1093/toxsci/kft171

[79] Mittleman, G., Call, S.B., Cockroft, J.L., Goldowitz, D., Matthews, D.B., \& Blaha, C.D. (2011). Dopamine dynamics associated with, and resulting from, schedule-induced alcohol self-administration: Analyses in dopamine transporter knockout mice. Alcohol, 45(4), 325-339. doi:10.1016/j.alcohol.2010.12.006

[80] Collier, G. \& Novell, K. (1967). Saccharin as a sugar surrogate. Journal of Comparative and Physiological Psychology, 64(3), 404-408. doi:10.1037/h0025203 
[81] Haussmann, M.F. (1933). The behavior of albino rats in choosing foods. II. Differentiation between sugar and saccharin. Journal of Comparative Psychology, 15(3), 419-428. doi: $10.1037 / \mathrm{h} 0074919$

[82] Rutkowska, M., Jamontt, J., \& Gliniak, H. (2006). Effects of cannabinoids on the anxietylike response in mice. Pharmacological Reports, 58(2), 200-206.

[83] Järbe, T.U., Andrzejewski, M.E., \& DiPatrizio, N.V. (2002). Interactions between the CB1 receptor agonist Delta 9-THC and the CB1 receptor antagonist SR-141716 in rats: Openfield revisited. Pharmacology, Biochemistry, and Behavior, 73(4), 911-919. doi:10.1016/S0091-3057(02)00938-3

[84] Gamage, T.F., Ignatowska-Jankowska, B.M., Muldoon, P.P., Cravatt, B.F., Damaj, M.I., \& Lichtman, A.H. (2015). Differential effects of endocannabinoid catabolic inhibitors on morphine withdrawal in mice. Drug and Alcohol Dependence, 146, 7-16. doi:10.1016/j.drugalcdep.2014.11.015

[85] Justinová, Z., Panlilio, L.V., Moreno-Sanz, G., Redhi, G.H., Auber, A., Secci, M.E.,...Goldberg, S.R. (2015). Effects of fatty acid amide hydrolase (FAAH) inhibitors in non-human primate models of nicotine reward and relapse.

Neuropsychopharmacology, 40(9), 2185-2197. doi:10.1038/npp.2015.62

[86] Murillo-Rodriguez, E., Palomero-Rivero, M., Millán-Aldaco, D., \& Di Marzo, V. (2013). The administration of endocannabinoid uptake inhibitors OMDM-2 or VDM-11 promotes sleep and decreases extracellular levels of dopamine in rats. Physiology \& Behavior, 109, 88-95. doi:10.1016/j.physbeh.2012.11.00

[87] Vlachou, S., Nomikos, G.G., \& Panagis, G. (2006). Effects of endocannabinoid neurotransmission modulators on brain stimulation reward. Psychopharmacology, 188(3), 293-305. doi:10.1007/s00213-006-0506-0

[88] Adamczyk, P., McCreary, A.C., Przegalinski, E. Mierzejewski, P., Bienkowski, B, \& Filip, M. (2009). The effects of fatty acid amide hydrolase inhibitors on maintenance of cocaine and food self-administration and on reinstatement of cocaine-seeking and food-taking behavior in rats. Journal of Physiology and Pharmacology, 60(3), 119-125.

[89] Price, D.A., Owens, W.A., Gould, G.G., Frazer, A., Roberts, J.L., Daws, L.C., \& Giuffrida, A. (2006). $\mathrm{CB}_{1}$-independent inhibition of dopamine transporter activity by cannabinoids in mouse dorsal striatum. Journal of Neurochemistry, 101(2), 389-396. doi:10.1111/j.1471-4159.2006.04383.x

[90] Perdikaris, P., Tsarouchi, M., Fanarioti, E., Natsaridis, E., Mitsacos, A., \& Giompres, P. (2018). Long lasting effects of chronic WIN55,212-2 treatment on mesostriatal dopaminergic and cannabinoid systems in the rat brain. Neuropharmacology, 129, 1-15. doi:10.1016/j.neuropharm.2017.11.005 
[91] Cheer, J.F., Wassum, K.M., Sombers, L.A., Heien, M.L., Ariansen, J.L., Aragona, B.J.,...Wightman, R.M. (2007). Phasic dopamine release evoked by abused substances requires cannabinoid receptor activation. The Journal of Neuroscience, 27(4), 791-795. doi:10.1523/JNEUROSCI.4152-06.2007

[92] Wang, H., Treadway, T., Covey, D.P., Cheer, J.F., \& Lupica, C.R. (2015). Cocaine-induced endocannabinoid mobilization in the ventral tegmental area. Cell Reports, 12(12), $1997-$ 2008. doi:10.1016/j.celrep.2015.08.041

[93] Gorriti, M.A., Rodríguez de Fonseca, F., Navarro, M., \& Palomo, T. (1999). Chronic (-)delta9-tetrahydrocannabinol treatment induces sensitization to the psychomotor effects of amphetamine in rats. European Journal of Pharmacology, 365(1-2), 133-142. doi:10.1016/s0014-2999(98)00851-6

[94] Lamarque, S., Taghzouti, K., \& Simon, H. (2001). Chronic treatment with delta(9)tetrahydrocannabinol enhances the locomotor response to amphetamine and heroin. Implications for vulnerability to drug addiction. Neuropharmacology, 41(1), 118-129. doi:10.1016/s0028-3908(01)00039-9

[95] Vlachou, S., Nomikos, G.G., \& Panagis, G. (2003). WIN 55,212-2 decreases the reinforcing actions of cocaine through CB1 cannabinoid receptor stimulation. Behavioural Brain Research, 141(2), 215-222. doi:10.1016/s0166-4328(02)00370-4

[96] Panlilio, L.V., Solinas, M., Matthews, S.A., \& Goldberg, S.R. (2007). Previous exposure to THC alters the reinforcing efficacy and anxiety-related effects of cocaine in rats. Neuropsychopharmacology, 32(3), 646-657. doi:10.1038/sj.npp.1301109

[97] Robertson, S.D., Matthies, H.J., \& Galli A. (2009). A closer look at amphetamine induced reverse transport and trafficking of the dopamine and norepinephrine transporters. Molecular Neurobiology, 39(2), 73-80. doi:10.1007/s12035-009-8053-4

[98] Bortolato, M., Campalongo, P., Mangieri, R.A., Scattoni, M.L., Frau, R., Trezza, V.,...Piomelli, D. (2006). Anxiolytic-like properties of anandamide transport inhibitor AM404. Neuropsychopharmacology, 31(12), 2652-2659. doi:10.1038/sj.npp.1301061

[99] Scherma, M., Justinová, Z., Zanettini, C., Panlilio, L.V., Mascia, P. Fadda, P.,...Goldberg, S.R. (2012). The anandamide transport inhibitor AM404 reduces the rewarding effects of nicotine and nicotine-induced dopamine elevations in the nucleus accumbens shell in rats. British Journal of Pharmacology, 165(8), 2539-2548. doi:10.1111/j.14765381.2011.01467.x 
[100] Thanos, P.K., Clavin, B.H., Hamilton, J., O’Rourke, J.R., Maher, T., Koumas, C., Miao, E.,...Kaczocha, M. (2016). Examination of the addictive and behavioral properties of fatty acid-binding protein inhibitor SBFI26. Frontiers in Psychiatry, 7, 54. doi:10.3389/fpsyt.2016.00054

[101] Murray, J.E. \& Bevins, R.A. (2010). Cannabinoid conditioned reward and aversion: Behavioral and neural processes. ACS Chemical Neuroscience, 1(4), 265-278. doi:10.1021/cn100005p

[102] Panagis, G., Mackey, B., \& Vlachou, S. (2014). Cannabinoid regulation of brain reward processing with an emphasis on the role of CB1 receptors: A step back into the future. Frontiers in Psychiatry, 5, 92. doi:10.3389/fpsyt.2014.00092

[103] Bortolato, M., Mangieri, R.A., Fu, J., Kim, J.H., Arguello, O., Duranti, A.,...Piomelli, D. (2007). Antidepressant-like activity of the fatty acid amide hydrolase inhibitor URB597 in a rat model of chronic mild stress. Biological Psychiatry, 62(10), 1103-1110. doi:10.1016/j.biopsych.2006.12.001

[104] Rademacher, D.J. \& Hillard, C.J. (2007). Interactions between endocannabinoids and stress-induced decreased sensitivity to natural reward. Progress in Neuropsychopharmacology \& Biological Psychiatry, 31(3), 633-641. doi:10.1016/j.pnpbp.2006.12.013

[105] Ward, S.J. \& Dykstra, L.A. (2005). The role of CB1 receptors in sweet versus fat reinforcement: Effect of CB1 receptor deletion, CB1 receptor antagonism (SR141716A) and CB1 receptor agonism (CP-55940). Behavioural Pharmacology, 16(5-6), 381-388. doi:10.1097/00008877-200509000-00010

[106] Morgan, D.J., Davis, B.J., Kearn, C.S., Marcus, D., Cook, A.J., Wager-Miller, J.,...Mackie, K. (2014). Mutation of the putative GRK phosphorylation sites in the cannabinoid receptor $1\left(\mathrm{CB}_{1} \mathrm{R}\right)$ confers resistance to cannabinoid tolerance and hypersensitivity to cannabinoids in mice. The Journal of Neuroscience, 34(15), 51525163. doi:10.1523/JNEUROSCI.3445-12.2014

[107] Dow-Edwards, D., \& Izenwasser, S. (2012). Pretreatment with $\Delta 9$-tetrahydrocannabinol (THC) increases cocaine-stimulated activity in adolescent but not adult male rats. Pharmacology Biochemistry and Behavior, 100(3), 587-591. doi:10.1016/j.pbb.2011.09.003

[108] Friedman, A. L., Meurice, C., \& Jutkiewicz, E. M. (2019). Effects of adolescent $\Delta 9$ tetrahydrocannabinol exposure on the behavioral effects of cocaine in adult SpragueDawley rats. Experimental and Clinical Psychopharmacology, 27(4), 326-337. doi:10.1037/pha0000276 


\section{Appendix A}

Table 1

Dopamine Recording Drug Groups

Fixed Potential

\begin{tabular}{ccc} 
Drug Pretreatment & Amperometry Drug Challenge & $n$ \\
\hline Vehicle & Vehicle & 4 \\
& AA-5-HT & 6 \\
& ACEA & 4 \\
AA-5-HT & Cocaine & 6 \\
& Vehicle & 6 \\
ACEA & AA-5-HT & 7 \\
& Cocaine & 6 \\
& Vehicle & 5 \\
& ACEA & 5 \\
& Cocaine & 5 \\
\hline
\end{tabular}

Note. AA-5-HT = arachidonoyl serotonin; ACEA = arachidonoyl-2'-chloroethylamide. 
A
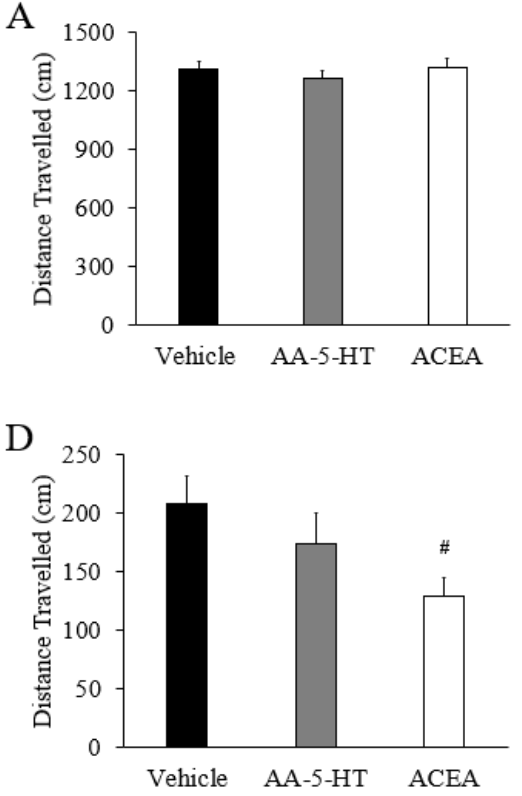

B

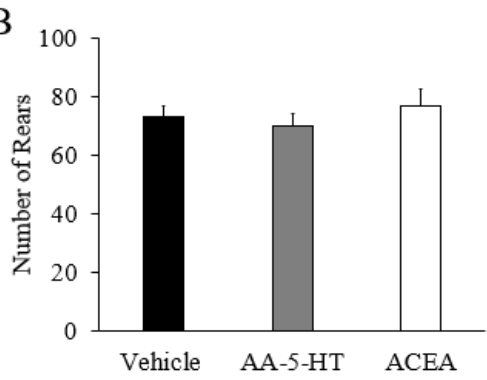

$\mathrm{E}$

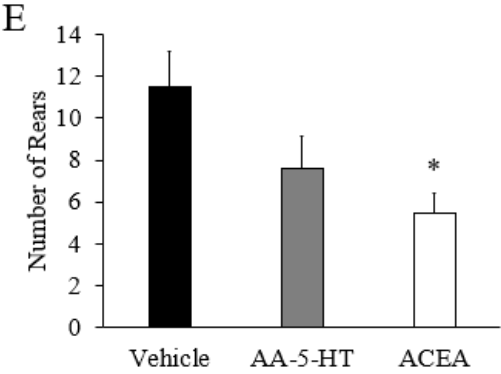

$\mathrm{C}$

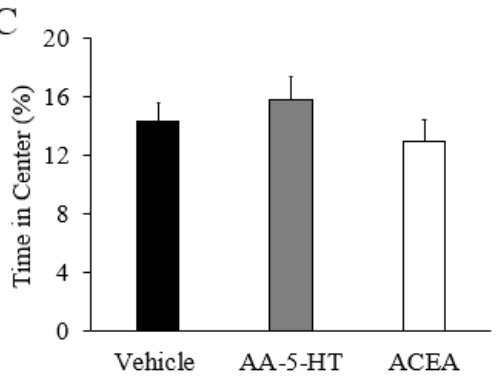

F

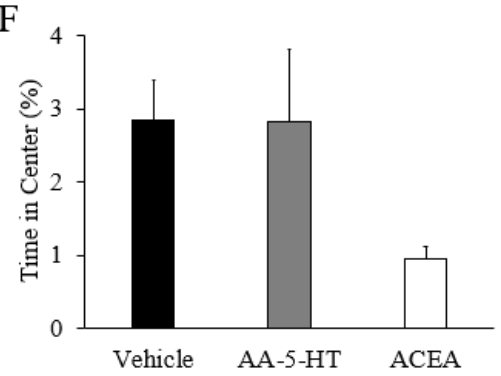

Figure 1. Baseline differences in locomotor activities in the OF were averaged into $10 \mathrm{~min}$ blocks and did not differ on (A) distance travelled, (B) number of rears, or (C) percent time in center in mice pretreated with vehicle, arachidonoyl serotonin (AA-5-HT), or arachidonyl-2'chloroethylamide (ACEA). Following an injection of the same pretreatment drug, there was a near significant difference in (D) distance travelled, a significant difference in number of rears, and no significant difference in $(\mathrm{F})$ percent time in center. All data is presented as mean $\pm \mathrm{SEM}$. \# indicates near significance at $p<.075$, and * indicates significance relative to vehicle pretreated mice at $p<.05$. 
A

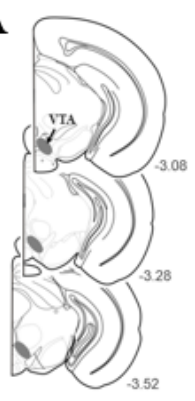

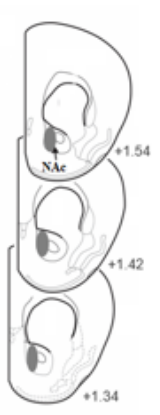
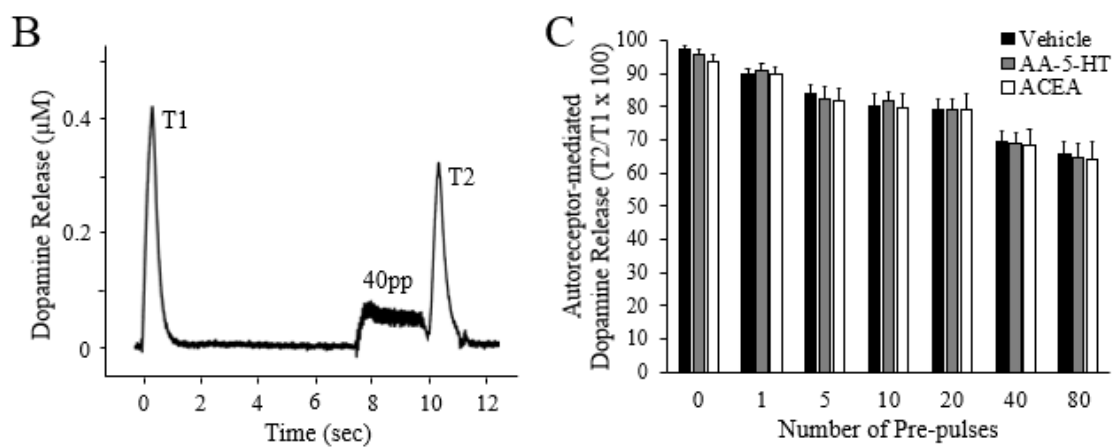

Figure 2. (A) Representative coronal sections of the mouse brain (adapted from the atlas of Paxinos \& Franklin, 2001), with gray-shaded areas indicating the placements of stimulating electrodes in the ventral tegmental area (VTA) and amperometric recording electrodes in the nucleus accumbens (NAc). Numbers correspond to mm from bregma. (B) A representative amperometric recording during the autoreceptor functioning test and (C) autoreceptor-mediated dopamine release displayed as means \pm SEMs following pre-pulses. Chronic pretreatment with either AA-5-HT (arachidonoyl serotonin) or ACEA (arachidonyl-2'-chloroethylamide) did not alter dopamine autoreceptor functioning in the NAc. 

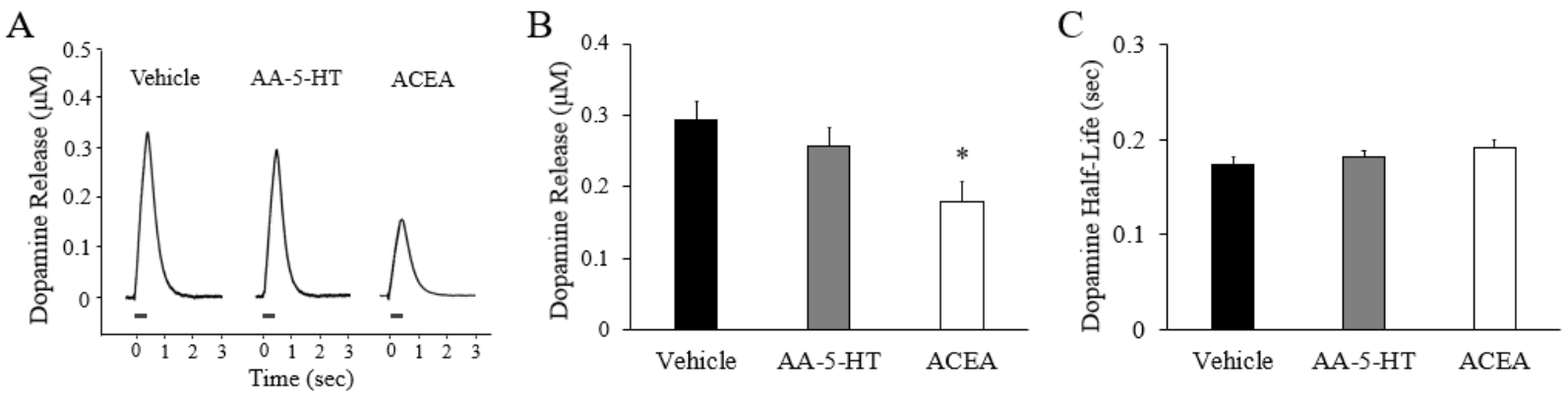

Figure 3. (A) Representative stimulation-evoked dopamine release responses following chronic pretreatment with vehicle, arachidonoyl serotonin (AA-5-HT), or arachidonyl-2'chloroethylamide (ACEA). (B) Dopamine release and (C) dopamine synaptic half-life in means \pm SEMs following drug pretreatment. * indicates a significant decrease relative to vehicle pretreatment at $p<.05$. 

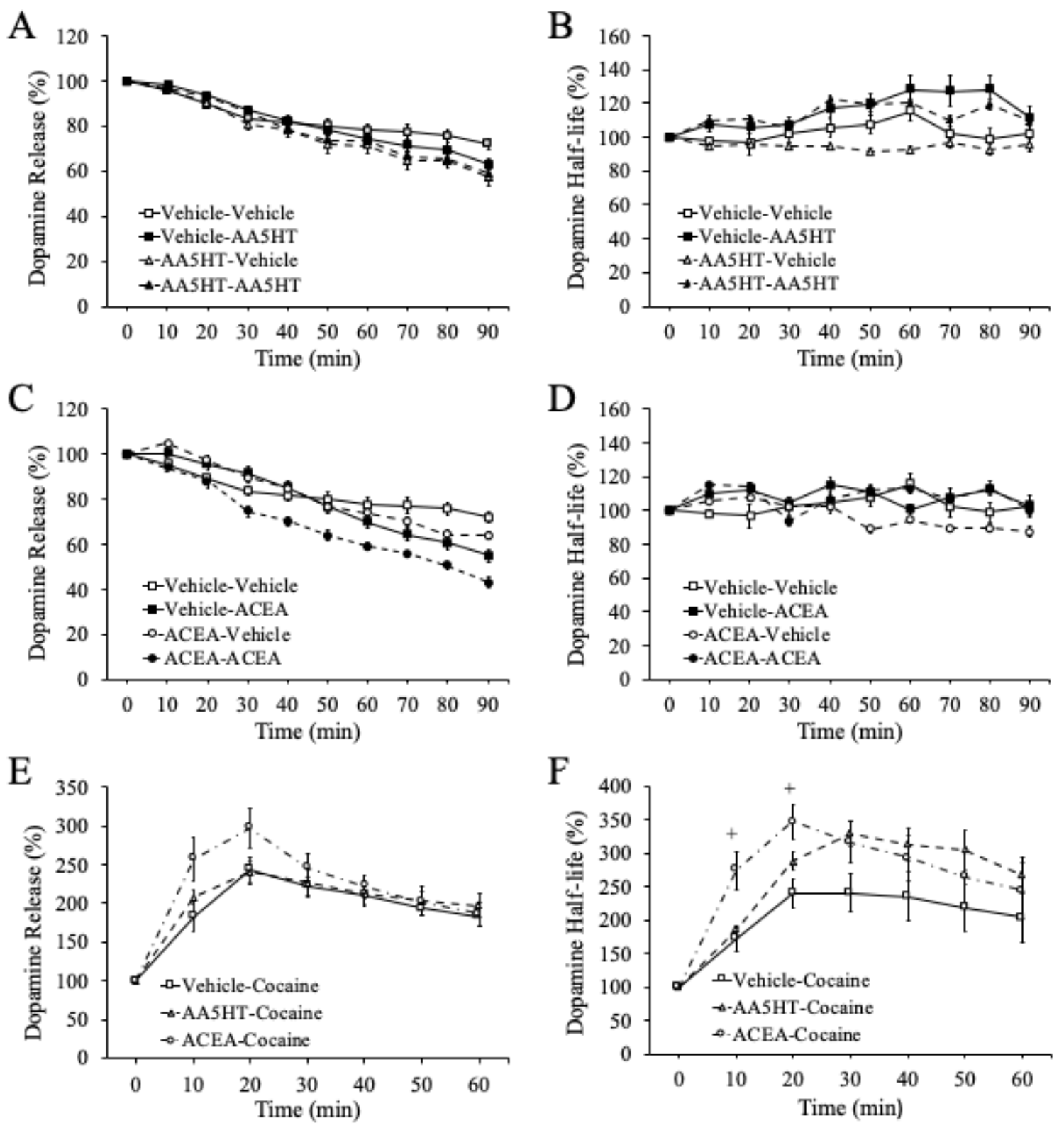

Figure 4. Percent change in dopamine release and half-life following drug challenges. The figure legend indicates the pretreatment drug then the drug challenge such that vehicle-vehicle represents mice that received vehicle pretreatment and vehicle drug challenge. Pretreatment of vehicle or arachidonoyl serotonin (AA-5-HT) on percent change in dopamine (A) release or (B) half-life presented as means \pm SEMs. Pretreatment of vehicle or arachidonyl-2'chloroethylamide (ACEA) on percent change in dopamine $(\mathrm{C})$ release or $(\mathrm{D})$ half-life presented as means \pm SEMs. Percent change in dopamine $(E)$ release and $(F)$ half-life following cocaine administration in mice pretreated with vehicle, AA-5-HT, or ACEA. + indicates $p<.06$. 

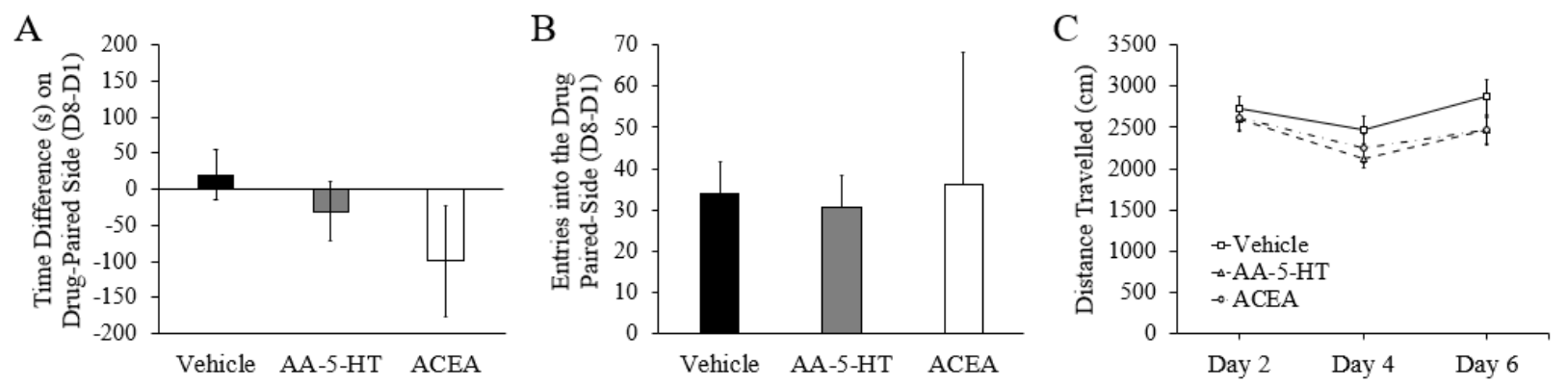

Figure 5. Time differences within, entries into, and distance travelled on the drug-paired side. (A) Drug challenge on time spent in the drug-paired side presented as day one subtracted from day eight. (B) Drug challenge on entries into the drug-paired side presented as day one subtracted from day eight. (C) Drug challenge on distance travelled on drug-paired days. AA-5$\mathrm{HT}=$ arachidonoyl serotonin and ACEA = arachidonyl-2'-chloroethylamide. 

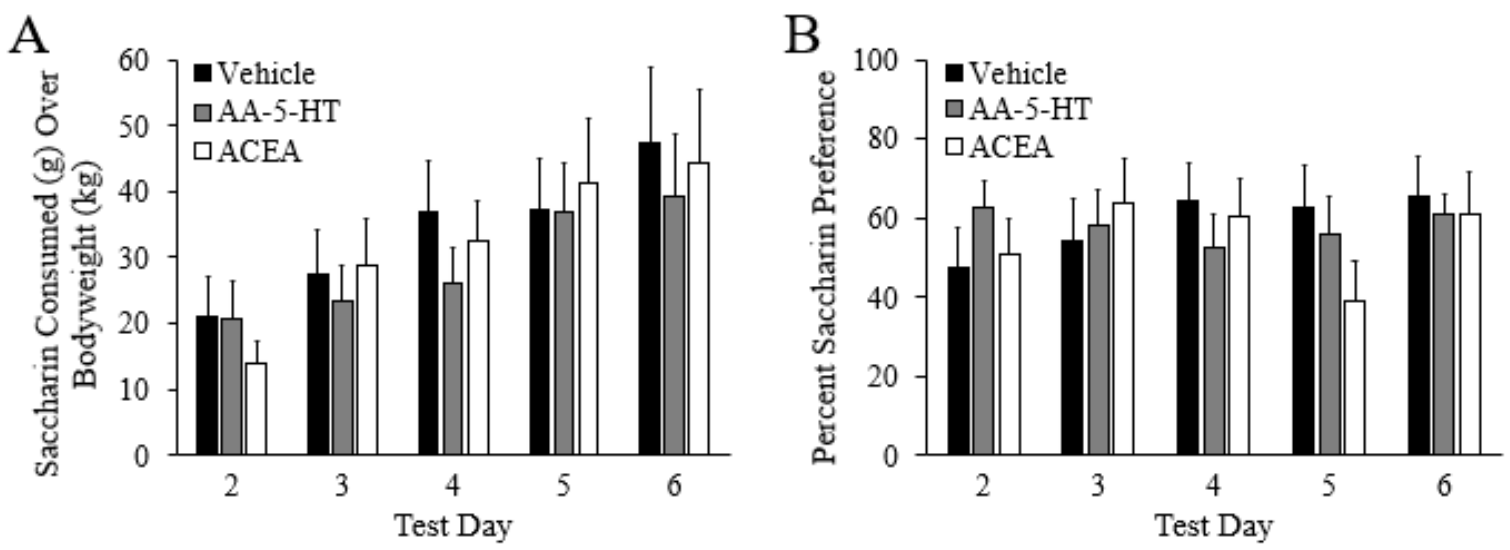

Figure 6. Drug challenge on saccharin preference when presented with one bottle of saccharin and one of water. (A) Drug challenge on saccharin consumed over body weight. (B) Drug challenge on saccharin consumed as a percent of total liquid consumed. AA-5-HT $=$ arachidonoyl serotonin and ACEA = arachidonyl-2'-chloroethylamide. 